\title{
Advances in altimetric snow depth estimates using bi-frequency SARAL/CryoSat-2 Ka/Ku measurements.
}

\author{
Florent Garnier ${ }^{1}$, Sara Fleury ${ }^{1}$, Gilles Garric ${ }^{2}$, Jérôme Bouffard ${ }^{3}$, Michel Tsamados ${ }^{4}$, Antoine Laforge ${ }^{5}$, \\ Marion Bocquet ${ }^{1}$, Rénée Mie Fredensborg Hansen ${ }^{3}$, and Frédérique Remy ${ }^{1}$ \\ ${ }^{1}$ Laboratoire d'Etudes en Géophysique et Océanographie Spatiales (LEGOS), CNRS/UMR5566, Université Paul Sabbatier, \\ 31400 Toulouse, France \\ ${ }^{2}$ Mercator Ocean, Ramonville Saint Agne, 31520, France \\ ${ }^{3}$ ESA (European Space Agency), Earth Observation Directorate, Via Galileo Galilei, 2-00044 Frascati, Italy \\ ${ }^{4}$ Centre for Polar Observation and Modelling, Department of Earth Sciences, University College London, London, WC1E \\ 6BT, UK \\ ${ }^{5}$ Serco c/o ESA, Earth Observation Directorate, Via Galileo Galilei, 2-00044 Frascati, Italy
}

Correspondence: F. Garnier (florent.garnier@legos.obs-mip.fr)

\begin{abstract}
Although snow depth on sea ice is a key parameter for Sea Ice Thickness (SIT), there currently does not exist reliable estimations. In Arctic, nearly all SIT products use a snow depth climatology (the Warren-99 modified climatology, W99m) constructed from in-situ data obtained prior to the first significant impacts of climate change. In Antarctica, the lack of information on snow depth remains a major obstacle in the development of reliable SIT products. In this study, we present the latest version of the Altimetric Snow Depth (ASD) product computed over both hemispheres from the difference of the radar penetration into the snow pack between the CryoSat-2 Ku-band and the SARAL Ka-band frequency radars. The ASD solution is compared against a wide range of snow depth products including model data (Pan-Arctic Ice-Ocean Modeling and Assimilation System (PIOMAS) or its equivalent in Antarctica the Global Ice-Ocean Modeling and Assimilation System (GIOMAS), the MERCATOR model and NASA's Eulerian Snow On Sea Ice Model (NESOSIM, only in Arctic)), the Advanced Microwave Scanning Radiometer 2 (AMSR-2) passive radiometer data, and the Dual-altimeter Snow Thickness (DuST) Ka-Ku product (only in Arctic). It is validated in the Arctic against in-situ and airborne validation data. These comparisons demonstrate that ASD provide a consistent snow depth solution, with space and time patterns comparable with those of the alternative Ka$\mathrm{Ku}$ DuST product, but with a mean bias of about $6.5 \mathrm{~cm}$. We also demonstrate that ASD is consistent with the validation data. Comparisons with Operation Ice Bridge's (OIB) airborne snow radar in Arctic during the period of 2014-2018 show a correlation of 0.66 and a RMSE of about $6 \mathrm{~cm}$. Furthermore, a first-guess monthly climatology has been constructed in Arctic from the ASD product, which shows a good agreement with OIB during 2009-2012. This climatology is shown to provide a better solution than the W99m climatology when compared with validation data. Finally, we have characterised the SIT uncertainty due to the snow depth from an ensemble of SIT solutions computed for the Arctic by using the different snow depth products previously used in the comparison with the ASD product. During the period of 2013-2019, we found a spatially averaged SIT mean standard deviation of $20 \mathrm{~cm}$. Deviations between SIT estimations due to different snow depths can reach up to $77 \mathrm{~cm}$. Using the ASD data instead of W99m to estimate SIT over this time period leads to a reduction of the average SIT of about $30 \mathrm{~cm}$.
\end{abstract}


https://doi.org/10.5194/tc-2021-79

Preprint. Discussion started: 13 April 2021

(c) Author(s) 2021. CC BY 4.0 License.

\section{(c) (i)}

\section{Introduction}

Since the launch of CryoSat-2 (CS-2) in 2010 (Wingham et al., 2006; Parrinello et al., 2018), Sea Ice Thickness (SIT) observations are routinely derived from altimetric measurements. The principle is to measure the emerged fraction of the sea ice, called the sea ice freeboard, from differences between the heights in leads (cracks in the ice referring to the local sea level) and the heights of the ice floes (Laxon et al., 2003). By integrating such sea ice freeboard estimations in the hydrostatic equilibrium equation, several SIT products have been computed (e.g., Laxon et al., 2013; Kwok and Cunningham, 2015; Guerreiro et al., 2017; Landy et al., 2019; Laforge et al., 2020).

Among the parameters involved in the SIT calculation, the snow depth over sea ice (SD) is one of the most significant contributors to the overall SIT uncertainty (e.g., Giles et al., 2007; Zygmuntowska et al., 2014; Guerreiro et al., 2016). For example, it is necessary to account for the sea ice sinking due to snow loading (Laxon et al., 2013) and for the decrease in altimetric radar speed as it penetrates into the snow pack (Kwok and Cunningham, 2015; Mallett et al., 2020). More generally, the snow cover has strong impacts on the sea ice (e.g., Massom et al., 2001; Powell et al., 2005; Bin et al., 2008; Sturm and Massom, 2009; Ricker et al., 2014) that affects the entire climate system (e.g., Ingram et al., 1989; Ledley, 1991; Eicken et al., 1995; Singarayer et al., 2006). Because of its high albedo and a low thermal conductivity, the snow regulates the transfer of solar heat energy of the ice-ocean interface (e.g., Grenfell and Maykut, 1977; Sturm et al., 1997). It acts as an insulator, slowing down sea ice melt in summer and slowing down sea ice growth in winter (e.g., Perovich et al., 2003; Sturm and Massom, 2016). The snow cover also modifies the surface roughness that impacts the ice/air drag coefficient and transfer coefficients of latent and sensible heat fluxes (Andreas et al., 2005).

Despite evidence of its major importance, the snow cover over sea ice is still not sufficiently known. Until now, nearly all SIT products in Arctic are computed using the snow depth of the Warren-99 modified climatology (W99m). W99m is mainly constructed using snow depth observations obtained from the Soviet North Pole drifting stations based in the central Arctic, collected during the last century (1950-1980s) (Warren et al., 1999). Considering the ongoing rapid modifications of the Arctic due to climate change, several studies have shown these data to be outdated, even with the modification of snow depth reduction (by 50\%) applied over the seasonal ice zone (Kurtz and Farrell, 2011; Kern et al., 2015; Kwok et al., 2011). More recently, Shalina and Sandven (2018) have created an improved snow depth climatology taking into account snow depth observations obtained during campaigns over seasonal ice, however with data collected mainly in the 1960's, 1970's and 1980's. Apart from the data used to construct these climatologies, several campaigns have provided snow depth measurements in Arctic. Between 1997 and 1998, the Surface HEat Budget of the Arctic Ocean (SHEBA) project has highlighted the complex temporal and spatial snow depth variations (Perovich et al., 1999; Sturm et al., 2002). The Ice Mass Balance buoys (IMB), originally deployed by the U.S. Army Cold Regions Research and Engineering Laboratory (CRREL)-Dartmouth Mass Balance Program during the SHEBA project have measured snow depths since the 2000s. It allows for monitoring changes of the sea ice volume in key areas of the Arctic (Richter-Menge et al., 2006). Since 2003, the CRYOsat Validation Experiment (CryoVEx) campaigns (Haas et al., 2006; Helm et al., 2006) have provided data with the main goal of investigating radar penetrations into ice and snow cover.Their measurements include bi-frequency altimetry snow depth estimations as of 2017 (see Sect. 3.3). In 
https://doi.org/10.5194/tc-2021-79

Preprint. Discussion started: 13 April 2021

(c) Author(s) 2021. CC BY 4.0 License.

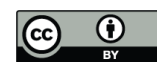

2003, the AMSR-Ice03 campaign (Sturm et al., 2006) was carried out in the Beaufort sea region to validate the Advanced Microwave Scanning Radiometer for the Earth Observing System (AMSR-E) passive microwave snow depth data. The same year, an equivalent mission (the Antarctic Remote Sensing Experiment, ARISE) took place in East Antarctica (Massom et al., 2006). Since 2009, and until their final campaign in 2020, the Operation Ice Bridge (OIB, see Sect. 3.3) campaigns have each year between March and April provided airborne snow depth measurements (Kurtz et al., 2013; Koenig et al., 2010) using a Frequency Modulated Continuous Wave (FMCW) snow radar (Kurtz and Farrell, 2011). Note also, that Webster et al. (2014) assesses spring snow depth distribution on the Arctic sea ice from 2009-2013 airborne OIB radar observations. In parallel, insitu snow thickness data were collected in 2009 at the Danish GreenArc 2009 ice camp in the North of Greenland (Farrell et al., 2011). Finally, between February and March 2015, snow depth was measured in the Nansen Basin during the Norwegian young sea ICE (N-ICE 2015) expedition (Granskog et al., 2016), demonstrating among others the impact of heavy precipitations on thin ice growth (Merkouriadi et al., 2017). Hence, several campaigns have been conducted during the last two decades in the Arctic all of which has provided crucial information on the Arctic snow depth and proved invaluable as reference data.

Compared to the Arctic, snow depth measurements, and more generally sea ice in-situ data, are very limited in Antarctica. Actually, several CryoVEx and OIB missions have been conducted in Antarctica, but consistent data sets are still under validation and not fully available. To the best of our knowledge, only the meereis data portal (https://www.meereisportal.de/) provides snow buoys data of snow accumulation (Grosfeld et al., 2016) (for both hemispheres), but the conversion to snow depth is not trivial and is, for instance, limited by the flooding of ice floes due to the heavy snow loading occurring in Antarctic. Currently, the main expedition providing snow depth data in the Southern hemisphere, is the Antarctic Sea Ice Process and

75 Climate (ASPeCt) program (Worby et al., 2008a), established in 1996 to model the role of Antarctic sea ice in the coupled atmosphere-ice-ocean system.

At a basin scale, several sea ice models produce snow accumulation estimations from atmospheric reanalyses. These are converted into snow depth over sea ice by considering sea-ice drifting and thermodynamic transfers of the coupled sea ice and snow system (Blanchard-Wrigglesworth et al., 2015; Lecomte et al., 2011). Likely due to biases in precipitation inputs and omission of snow processes, these global sea ice models hardly reproduce consistent on-ice snow depths (e.g., Holland et al., 1993; Serreze et al., 2000; Déry and Tremblay, 2004; Leonard and Maksym, 2011; Blazey et al., 2013). Notz (2012) states that an improved representation of the snow on sea ice in model is the most urgent task, and recently, Kaminski et al. (2018) argued that assimilating snow depth products could considerably increase sea ice model performances.

Therefore, a solution allowing to provide large scale information on the spatial and temporal variation of the snow cover and to improve the performance of seasonal sea-ice forecasts, is to use satellite data. For now, only few data sets exist. The first snow depth estimates come from the passive radiometric data. Among the various sensors that have been deployed (e.g., Scanning Multichannel Microwave Radiometer (SMMR), Chang et al. (1987) or Special Sensor Microwave/Imager (SSM/I) Grody (1991) ), the most relevant estimations of snow depth over sea ice have been calculated from spectral vertical gradients of brightness temperatures (Comiso et al., 2003; Worby et al., 2008b) of the Advance Microwave Scanning Radiometer of the

90 Earth system (AMSR-E, from 2002 to 2011, Kelly (2009)) and its successor, the Advance Microwave Scanning Radiometer-2 (AMSR-2, from 2012, Lee et al. (2015)). In spite of the relevant long term availability of data, the commonly used snow depth 
https://doi.org/10.5194/tc-2021-79

Preprint. Discussion started: 13 April 2021

(c) Author(s) 2021. CC BY 4.0 License.

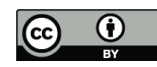

retrieval algorithm is not adapted for Multi Year Ice (MYI) zones (Brucker and Markus, 2013). Consequently, while this does not affect the southern hemisphere data availability (all sea ice is considered as seasonal ice), AMSR's official data in the Arctic are only calculated in First Year Ice (FYI) regions. As far as we know, the AMSR-2 product version of the University of Bremen (AMSR2B, Rostosky et al. (2018)) and very recently the Space-borne Observation for Detecting and Forecasting Sea Ice Cover Extremes project (SPICES) snow depth retrieval method (Mäkynen et al., 2020) are the only attempts to compute snow depth estimations in Arctic MYI zones. The data set developed from the work of Rostosky et al. (2018) is available, but has the inconvenience of being re-calibrated from OIB data which limits their availability to the months of March and April. With the same disadvantage of depending on OIB, Maaß et al. (2013) and Zhou et al. (2018) have proposed algorithms to retrieve snow depth from the Soil Moisture Ocean Satellite (SMOS), with mitigated results. Recently, Braakmann-Folgmann and Donlon (2019) proposed to compute snow depth by combining AMSR-2 and SMOS data with a neural network approach.

An alternative to passive microwave radiometry is to derive snow depth estimations from bi-frequency altimetric measurements. Recently, Armitage and Ridout (2015) and Guerreiro et al. (2016) have demonstrated this possibility by considering the difference of penetration between the CS-2 Ku-band frequency radar $(13.5 \mathrm{GHz})$, assuming its reflected near the snow/ice interface, and the SARAL/AltiKa Ka-band frequency radar $(35.7 \mathrm{GHz})$, assuming its reflected near the top of the snow pack (air/snow interface). Following Guerreiro et al. (2016), an Altimetric Snow Depth (ASD) product, covering the 2013-2016 winter period (time period of SARAL) in the Arctic, has been developed at the "Laboratoire d'Etudes en Géophysique et Océanographie Spatiales » (LEGOS) during the European Space Agency (ESA) CryoSat SciEnce-oriented data ANalysis over Sea-ICE areas (CryoSeaNICE) project. Meanwhile, Lawrence et al. (2018) also developed a bi-frequency altimeter snow depth product (the Dual-altimeter Snow Thickness, DuST) available for the Arctic. Similar to AMSR2B, the main difference between ASD and DuST is that DuST relies on a re-calibration of the Ka and Ku freeboards using OIB data, in this case to account for the difference of operating mode between CS-2 and SARAL (Synthetic Aperture Radar (SAR) versus Low Resolution Mode(LRM) modes). These two products are the only existing publicly available snow depth products from altimetry.

Studies have also estimated snow depth on sea ice in Antarctica (e.g., Kacimi and Kwok, 2020; Maksym and Markus, 2008). The recent work of Kacimi and Kwok (2020) estimated the Antarctic snow depth from the difference between the total freeboard obtained from ICESat-2 (IS2) lidar measurements and sea ice freeboards of CS-2. They show a very low variability of CS-2 freeboards compared to ICESat- 2 and that IS-2 freeboards explained $>90 \%$ of the variance in snow depth. They also highlight that validation of Antarctic sea ice parameters remains a challenge, since no seasonally or regionally diverse data sets from field records can be used to assess the large-scale satellite retrievals. Based on this, they urge that more sustained and extensive field measurements must be conducted. Finally, we note that a recent study of Fons et al. (2021), an update from the former approach experimented by Fons and Kurtz (2019), directly retrieves snow freeboard from CS-2 using a two-layer scattering model, and shows promise in estimations of SIT in over the Antarctic.

A recent study of Zhou et al. (2020b) presented an inter-comparison of available snow depth products from re-analyses, passive radiometry and altimetry (DuST). While this study provides similar comparisons between snow depth products, the main objective is here to present and assess an upgraded version of the ASD product (see Sect. 2), covering the 2013-2019 period in both hemispheres. In this study, we present an extensive comparison between the various existing snow depth data 
https://doi.org/10.5194/tc-2021-79

Preprint. Discussion started: 13 April 2021

(c) Author(s) 2021. CC BY 4.0 License.

\section{(c) (i)}

sets in the Arctic and Antarctica. The main part of this study is dedicated to a large temporal and spatial scales analysis of the different snow depth products. First, the ASD product is compared with snow depth estimations from AMSR-2, DuST (only in the Arctic) and sea ice models. These data sets are then assessed against OIB, CryoVEx and IMB snow depth data. Since neither OIB nor CryoVEx are available yet in Antarctica and ASPeCt does not cover the 2013-2019 time period, the comparison with validation data will only focus on the northern hemisphere. Thereafter, we show how ASD could alternatively provide a relevant climatological solution, allowing to have snow depth data beyond the limitation of the SARAL time period. The third part aims to quantify the SIT level of uncertainty due to the snow depth from an ensemble of SIT estimations calculated from the satellite and model snow depth datasets presented in the previous sections. Finally, we will conclude and discuss the results and provide reflections on how this snow depth product fits in with the upcoming High Priority Copernicus Candidate Mission; Copernicus Polar Ice and Snow Topography Altimeter (CRISTAL) (Kern et al., 2020).

\section{Data processing of ASD}

The Altimetric Snow Depth product (ASD) presented here, is an upgraded version of the data presented in Guerreiro et al. (2016). It has been developed at the LEGOS laboratory in the framework of the ESA CryoSat+ Antarctic Ocean (CSAO+, http://cryosat.mssl.ucl.ac.uk/csao/index.html) and Polar+ Snow on Ice projects. It is freely available on the AVISO+/ODATIS (Archiving, Validation and Interpretation of Satellite Oceanographic data/Online Data Extraction Service) national data centres since mid-2020. The ASD product includes data from March 2013 to October 2019 provided on a monthly basis for the six winter months (from November to April in the Arctic and from May to October in Antarctica). It is projected onto a $500 \times 500$ EASE2 grid with a $12.5 \mathrm{~km}$ pixel size resolution. The snow depth calculation is based on the difference of penetration between the Ka-band range altimeter of SARAL (which is assumed to be reflected near the top of the snow pack, the air/snow interface) and the Ku-band range altimeter of CS-2 (which is assumed to be reflected near the snow/ice interface). The main assumption is that the difference between these two freeboards is only due to the penetration of the Ku radar in the snow pack, and that the Ku radar penetrates fully to the snow/ice interface. For that purpose, CS-2 Ku-band waveforms in Pseudo LRM (PLRM) are extracted from Geophysical Ocean Products (GOP) https://earth.esa.int/documents/10174/125272/ CryoSat-Baseline-C-Ocean-Product-Handbook generated by the ESA CryoSat Ocean Processor (Bouffard et al., 2018a). The Ka band SARAL/AltiKa waveforms are extracted from the CNES Sensor Geophysical Data Records (sgdr) T official products. The use of a degraded version of the CS-2 SAR waveforms (the PLRM mode), allows to have a footprint in accordance with the LRM mode of SARAL/AltiKa waveforms. Note, that the ASD product presented in this article does not includes the degraded CS-2 SARin mode data since we did not use the latest PLRM product (Baseline B is used). Since SARin data are now included in the fully reprocessed PLRM GOP product (Baseline C), the next version of the ASD product will include SARin data.

The first step to compute ASD data consists in extracting heights, $H$, from both $\mathrm{Ku}$ and $\mathrm{Ka}$ band satellite waveforms following Eq. (1):

$H=$ alt $-\left(\right.$ range $-\left(\right.$ tropo $_{d r y}+$ tropo $_{w e t}+i o n o+M S S+$ tide $_{\text {ocean }}+$ tide $\left.\left._{\text {bar }}\right)\right)$, 
https://doi.org/10.5194/tc-2021-79

Preprint. Discussion started: 13 April 2021

(c) Author(s) 2021. CC BY 4.0 License.

(c) (i)

where alt is the satellite altitude and range is the altimetric range retracked from the waveforms. tropo $_{d r y}$ is the dry tropospheric correction, tropo $_{\text {wet }}$ is the wet tropospheric correction, iono is the ionospheric correction, MSS is the DTU15 Mean Sea Surface correction (Andersen and Knudsen, 2015), tide $_{\text {ocean }}$ is the oceanic tide corrections and tide bar is the barometer tide correction.

The surface classification between heights corresponding to ocean surfaces (leads) and heights of sea ice surfaces (ice floes) is performed using the waveform pulse-peakiness (PP) criteria calculated from the waveforms (Eq. (2)):

$P P=\frac{\max (W F)}{\sum_{i=1}^{N_{W F} W F_{i}}}$

where $W F$ is the discrete waveform echoes and $N_{W F}$ is the number of along-track measurements. Following Guerreiro et al. (2017), surfaces with a PP larger than 0.3 are considered as leads and surfaces with a PP smaller than 0.1 are considered as sea ice floes. Observations with a PP between 0.1 and 0.3 are considered as mixed echoes and are discarded.

Altimetric ranges (range parameter in Eq. (1)) of leads and floes are thereafter calculated using the Threshold First Maximum Retracker Algorithm (TMFRA; Helm et al., 2014) with a 50\% threshold. A $25 \mathrm{~km}$ median filter is then applied to the 20 $\mathrm{Hz}$ along-track surface height of sea ice floes and sea ice leads. For each observation, the Sea Level Anomalies (SLA) under floes are calculated as the median value of all leads in a $25 \mathrm{~km}$ radius around the considered along-track point. Freeboard heights are computed by $f b=H_{\text {floe }}-H_{\text {lead }}$, where $H_{\text {floe }}$ is the heights of the ice floes and $H_{\text {leads }}$ the heights of the leads. Finally, a $50 \mathrm{~km}$ median smoothing is applied to the retrieved freeboards. In the first ASD data version (Guerreiro et al., 2016), snow depths were only calculated at CS-2 and SARAL crossing track points. For this version, snow depths are calculated from the difference between monthly EASE2 gridded freeboards as: $s d_{r}=f b_{K a}-f b_{K u}$, where $s d_{r}$ is a radar snow depth. Furthermore, to compute the snow depth $(s d)$, we need to take into account the decreasing of the Ku radar echo velocity when it penetrates into the snow pack (Ulaby et al., 1986; Kwok and Cunningham, 2015):

$s d=s d_{r} \times\left(1+0.51 \times \rho_{s}\right)^{(-1.5)}$,

where $\rho_{s}$ is the snow density, set to $300 \mathrm{~kg} / \mathrm{m}^{3}$. Note this formulation agrees with the conventional interpretation to correct for the slower wave propagation speed through snow, as recently shown in Mallett et al. (2020).

To estimate snow depth uncertainties, we assume that errors are unbiased, uncorrelated and follow the Gaussian propagation law. The snow depth uncertainty is then given by:

$\epsilon_{s d}=\sqrt{\left(\epsilon_{s d_{r}} \times C\right)^{2}+\left(s d_{r} \times B \times \epsilon_{\rho_{s}}\right)^{2}}$

185 with

$C=\left(1+0.51 \times \rho_{s}\right)^{-1.5}, \quad B=-1.5 \times 0.51 \times\left(1+0.51 \times \rho_{s}\right)^{-2.5}, \quad \epsilon_{s d_{r}}=\sqrt{\epsilon_{f b_{K a}}^{2}+\epsilon_{f b_{\text {radar } K u}}^{2}} \quad$ and $\quad \epsilon_{\rho_{s}}=3.2$.

The freeboard uncertainties $\epsilon_{f b}=\sqrt{\epsilon_{H_{l e a d s}}^{2}+\epsilon_{H_{\text {floes }}}^{2}}$ are calculated along-track from the statistical dispersion of heights in a $12.5 \mathrm{~km}$ radius. Since sea ice topography can significantly vary within this area, we assume that the statistical dispersion of 
https://doi.org/10.5194/tc-2021-79

Preprint. Discussion started: 13 April 2021

(c) Author(s) 2021. CC BY 4.0 License.
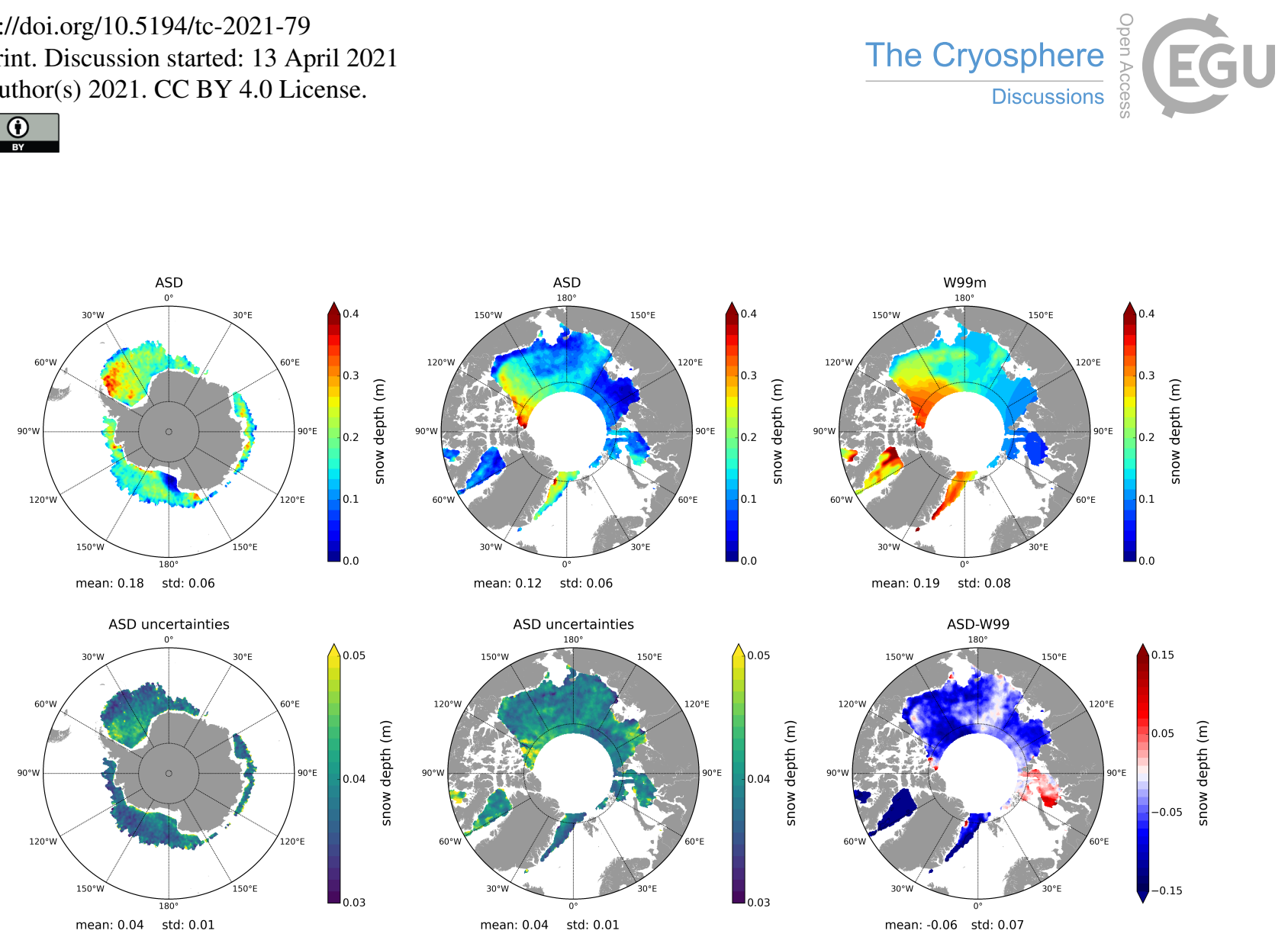

Figure 1. Maps of (first column) the Altimetric Snow Depth (ASD) annual mean (top) snow depth and its uncertainties (bottom) in Antarctica and (second column) the Arctic for 2015. (Third column) presents the annual mean snow depth map of the Warren-99 modified (W99m) climatology (top) and its difference (ASD-W99m) in the Arctic (bottom) in 2015.

floes is the same as that of the leads.

$\epsilon_{H_{\text {floes }}}^{2}=\frac{\sigma_{H_{\text {leads }}}}{N_{\text {floes }}}$ and $\epsilon_{H_{\text {leads }}}^{2}=\frac{\sigma_{H_{\text {leads }}}}{N_{\text {leads }}}$

Using this methodology, Fig. 1 presents an example of ASD snow depth estimations and its associated uncertainties in the two hemispheres. In the Arctic, it also shows that these data are different from the Warren 99 modified (W99m) climatology, where nearly everywhere the W99m climatology exhibits thicker snow layers over sea ice. The ASD mean level of uncertainties (of about $4 \mathrm{~cm}$ on average with standard deviation of $1 \mathrm{~cm}$ ) are smaller than the deviations between these two products (on average about $6 \mathrm{~cm}$ with standard deviation of $7 \mathrm{~cm}$ ).

\section{External data sets}

This section presents the various snow depth data sets used in this study. For both hemispheres, the time period of model and satellite products that have been used is explained in Fig. 2 (ranges from 2014-2019 for the Arctic, and 2013-2019 for the Antarctic with limitations for some data products for both hemispheres). 
https://doi.org/10.5194/tc-2021-79

Preprint. Discussion started: 13 April 2021

(c) Author(s) 2021. CC BY 4.0 License.

(c) (i)

\subsection{Satellite data}

\subsubsection{DuST}

Similar too ASD data, DuST (Lawrence et al., 2018) relies on the difference of penetration between SARAL Ka-band and CS-2 Ku-band radar altimeters. However, unlike the ASD product (which uses the CS-2 PLRM data, see Sect. 2), freeboard estimates of CS-2 and SARAL are calibrated against data from National Aeronautics and Space Administration's (NASA's) OIB airborne measurements to align the freeboard observations from SARAL/AltiKa with the snow/air interface, and the freeboard observations from CS-2 with the snow/ice interface. Although this method provides a generic approach adaptable to different footprints (e.g., the Ice, Cloud, and land Elevation Satellites, (ICESat-1 and 2)), it has the disadvantage of being dependent on the OIB data which are mainly located near the Canadian Archipelago ( and the Beaufort Sea, and only obtained during March and April. The DuST data are provided on a $1.5^{\circ}$ longitude x $0.5^{\circ}$ latitude grid by the Centre for Polar Observation and Modelling, University College London (www.cpom.ucl.ac.uk/DuST).

\subsubsection{AMSR-2}

The Advance Microwave Scanning Radiometer 2 (AMSR-2) is a passive radiometer on-board the Japan Aerospace Exploration Agency (JAXA) Global Change Observation Mission-Water (GCOM-W) satellite launched in 2012. Snow depth on sea ice retrieval is based on the gradient ratio of vertically polarized brightness temperature at 19 and $37 \mathrm{GHz}$ (Markus and Cavalieri, 1998), and two snow depth products are available. The first product (AMSR2-NSIDC), described in Meier et al. (2018), is accessible on the National Snow and Ice Data Center (NSIDC, https://nsidc.org/data/AU_SI12/versions/1). It provides daily L3 snow depth data in $12.5 \mathrm{~km} \times 12.5 \mathrm{~km}$ stereopolar grids constructed as five day running averages. Data are only calculated over FYI (with MYI concentration of less than 20\%). This is due to the fact that MYI has a spectral signature similar to snow cover over FYI Because of this limitation, we mainly focus on the Bremen AMSR-2 (AMSR2B) product (Rostosky et al., 2018) developed at the Institute of Environmental Physics of the University of Bremen. This product is available on a daily basis until 2019 on a polar stereographic grid with a $25 \mathrm{~km}$ x $25 \mathrm{~km}$ resolution. Unlike in AMSR2-NSIDC, March and April snow depth data are also calculated over MYI for AMSR2B. Other months are only available on FYI. Note that the algorithm used to calculate snow depth over MYI is also calibrated with observations from OIB.

\subsection{Model data}

\subsubsection{PIOMAS}

The pan-Arctic Ice-Ocean Modeling and Assimilation System (PIOMAS, GIOMAS in Antarctica) is a pan-Arctic coupled ocean and sea ice model developed for climate applications (Zhang and Rothrock, 2003). Snow depth data are provided on a daily basis in a 360 x 120 generalized curvilinear coordinate system from the PIOMAS model version 2.1 (http://psc.apl. uw.edu/research/projects/arctic-sea-ice-volume-anomaly/data/model_grid). The atmospheric surface forcing fields are issued 
https://doi.org/10.5194/tc-2021-79

Preprint. Discussion started: 13 April 2021

(c) Author(s) 2021. CC BY 4.0 License.

(c) (i)

Organisation for the Exploitation of Meteorological Satellites (EUMETSAT) is assimilated in near real time. A complete description can be found in Schweiger et al. (2011)

\subsubsection{MERCATOR}

In the framework of CMEMS (Copernicus Marine Environment Monitoring Service), Mercator Ocean implements a real time global analysis and forecasting system at $1 / 12^{\circ}$ resolution. This system is based on the Nucleus for European Modelling of the Ocean (NEMO) ocean platform (Madec et al., 2015) and driven by atmospheric conditions from the ECMWF (European Centre for Medium-Range Weather Forecasts) IFS (Integrated Forecast System) analysis and forecasting system. The sea ice model component is the Louvain-la-Neuve sea Ice Model (LIM2) (Fichefet and Maqueda, 1997; Vancoppenolle et al., 2012) The unique sea ice quantity assimilated within the system is the near real time sea ice concentration from OSI SAF provided by CMEMS. The accumulation of the snow depth onto sea ice originates from ECMWF snowfall forcing fields. A complete description can be found in Lellouche et al. (2018). Snow depth data used in this study has been provided in a monthly basis on the ORCA tripolar grid. This LIM-2 model configuration will be referred as the MERCATOR model.

\subsubsection{NESOSIM}

The NASA Eulerian Snow On Sea Ice Model (NESOSIM) is a 3D snow budget model configured to produce snow depth

and density over sea ice in the Arctic Ocean. Data used in this paper are snow depth monthly mean maps provided on a $100 \mathrm{~km} \times 100 \mathrm{~km}$ stereographic polar grid issued from the NESOSIM 1.0 configuration (Petty et al., 2018), freely available at https://earth.gsfc.nasa.gov/cryo/data/nasa-eulerian-snow-sea-ice-model-nesosim the Arctic System Reanalysis, version 1 (ASRv1). Snowfall data forcing field are the ECMWF ERA-Interim (ECMWF Re-Analysis-Interim) global reanalysis and a median of three reanalysis: the 55 years reanalysis of the Japanese Meteorological Agency (JRA-55), the NASA's Modern-Era Retrospective analysis for Research and Applications and the Arctic System Reanalysis, version 1 (ASRv1).

\subsection{Validation data}

\subsubsection{CRYOsat Validation EXperiment (CryoVEx)}

These airborne data are a joint effort of the DTU National Space Institute and ESA (in cooperation with the Alfred Wegener Institute, AWI). The main goal of the project is to quantify and validate CS-2's ability to measure SIT. Since 2003, the CryoVEx missions provides both laser (ALS) and Ku-band radar (ASIRAS) altimetric measurements. In addition, in 2017, the data include for the first time along-track total freeboards from the Ka-band KAREN altimeter (Haas et al., 2017), allowing to compute Ka-Ku snow depth estimations. These data have been developed by AWI in the context of the ESA CryoSeaNICE project. 
https://doi.org/10.5194/tc-2021-79

Preprint. Discussion started: 13 April 2021

(c) Author(s) 2021. CC BY 4.0 License.

(c) (i)
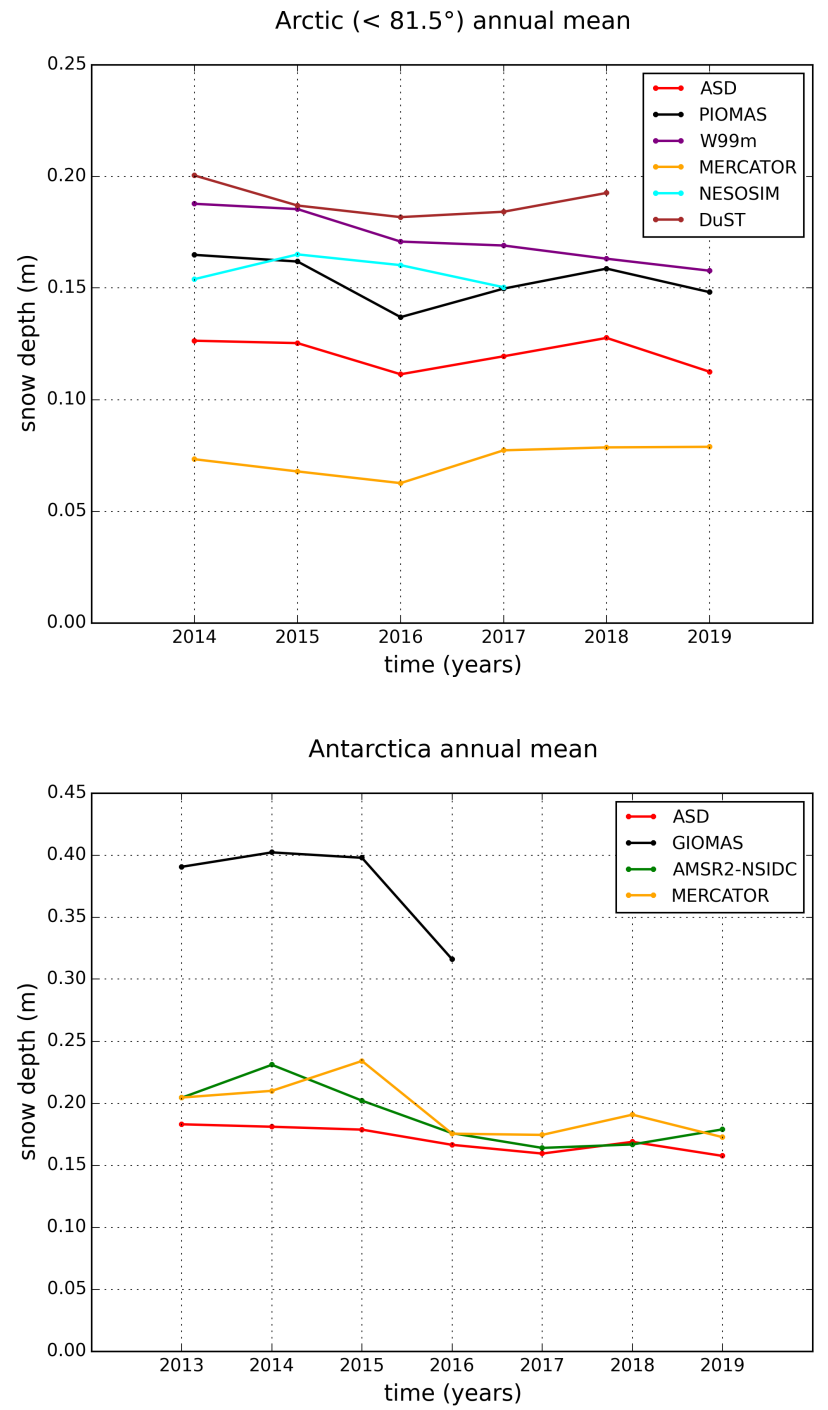

Figure 2. Times series of annual mean snow depth of the different products in both hemispheres. Annual means are calculated as the average of the spatial means of all monthly grid maps (only the winter months are considered). Note that the AMSR-2 data are not represented in the Arctic since the AMSR2-NSIDC product is only available over FYI and the AMSR2B product is only available at full spatial coverage (FYI and MYI) in March and April.

\subsubsection{Operation Ice Bridge (OIB)}

OIB is one of the largest airborne mission in polar regions aiming to determine sea ice properties. Among others, it carries a snow radar measuring the snow-air and snow-ice interfaces of the signal scattered by the area illuminated beneath the aircraft. All information concerning the different campaigns and instruments can be found in various literature (e.g., Newman et al., 
https://doi.org/10.5194/tc-2021-79

Preprint. Discussion started: 13 April 2021

(c) Author(s) 2021. CC BY 4.0 License.

(c) (i)

2014; Kurtz et al., 2013; Armitage and Ridout, 2015). OIB snow depth data presented in this paper are the NSIDC OIB Quicklook version (Kurtz et al., 2012 (Updated 2015; King et al., 2015) validated from in-situ data of the Bromine Ozone Mercury Experiment (BROMEX) campaign (Nghiem et al., 2013). These data are available at https://daacdata.apps.nsidc. org/pub/DATASETS/ICEBRIDGE/Evaluation_Products/. For comparison with the ASD data set, we compare with all spring campaigns during the period of 2014-2018. For comparison with the ASD climatology, we compare with all OIB spring campaigns during 2009-2012.

\subsubsection{Ice Mass Balance (IMB) buoys}

IMB data (Perovich et al., 2021) are issued from the U.S. Army CRREL-Dartmouth Mass Balance Buoy Program. They provide point measurement of the ice mass balance characterised by a combination of snow and ice conditions (Richter-Menge et al., 2006; Perovich and Richter-Menge, 2015) Snow depth data are collected at 4 hours intervals from acoustic sounders. In this study we analyse the data of three winters (2013-2014, 2014-2015 and 2015-2016). Note that we do not use the data of 2017 and 2018 because they are still provisional and subject to revision.

\section{Comparison between snow depth data}

\subsection{Methodology}

Model and satellite snow depth estimations are projected onto the same $500 \times 500$ EASE2 grid. For each product we compute monthly mean maps for the six winter months for both hemispheres from March 2013 to October 2019. These maps are provided for 2015 in the supplementary material (Figs. S1 to S13). Three statistical diagnosis are used to characterise the differences between the snow depth data sets:

1) The climatic annual mean, which is simply the average of all snow depth monthly maps.

2) The Mean Annual Variability (MAV), which is the average of snow depth (sd) annual standard deviation $\left(s t d_{y}(s d)\right.$ ) maps on all considered years $y$. The MAV is calculated at each grid point following Eq. (6):

$M A V=\frac{1}{N_{y}} \sum_{y}\left(s t d_{y}(s d)\right) \quad$ with $\quad s t d_{y}(s d)=\sqrt{\frac{1}{N_{m}} \sum_{m}\left(s d_{y, m}-\overline{s d_{y}}\right)^{2}}$,

where $s d_{y, m}$ is the monthly snow depth map of the month $m(m=11,12,01,02,03,04$ in the Arctic and $m=05,06,07,08,09,10$ in Antarctica) for the year $y$ and $\overline{s d_{y}}$ is the snow depth annual mean map of the year $y . N_{m}$ and $N_{y}$ are the number of months (six in our case) and the number of year in the considered time period, respectively.

3) The Mean Inter-annual Variability (MIV), which is the average of the six winter months $m$ inter-annual standard deviation $s t d_{m}(s d)$ maps over the 2013-2019 time period. The MIV is calculated at each grid point following Eq. (7):

$M I V=\frac{1}{N_{m}} \sum_{y}\left(s t d_{m}(s d)\right) \quad$ with $\quad s t d_{m}(s d)=\sqrt{\frac{1}{N_{y}} \sum_{y}\left(s d_{y, m}-\overline{s d_{m}}\right)^{2}}$ 
https://doi.org/10.5194/tc-2021-79

Preprint. Discussion started: 13 April 2021

(c) Author(s) 2021. CC BY 4.0 License.

\section{(c) (i)}

where $\overline{s d_{m}}$ is average snow depth map of the month $m$.

Comparisons with all in-situ and validation data are performed with a comparable methodology: snow depth model and satellite gridded maps are projected along in-situ tracks using a simple linear interpolation. Since airborne and in-situ are generally daily data, the comparisons are performed with the monthly maps corresponding to the day. Note, that when comparing the various snow depth data with the OIB snow radar data, at achieve a corresponding spatial scale, we have applied a $25 \mathrm{~km}$ window rolling mean for smoothing the OIB data. For now, the lack of available relevant snow depth data in Antarctica limits these comparisons to the Northern hemisphere.

\subsection{Comparison between satellite and model estimations}

\subsubsection{Results in the Arctic}

Here, we compare the ASD, DuST and AMSR2B snow depth data in the Arctic by considering the months of March and April over the 2014-2018 period (Fig. 3). Climatic annual means and inter-annual variability presented in Fig. 3 are the mean and the standard deviation of all monthly maps of March and April over this time period. Statistical diagnosis are summarised in Table A1. On average, the ASD data are about $3 \mathrm{~cm}$ lower than the AMSR2B data and $6 \mathrm{~cm}$ lower than the DuST data. ASD data present the stronger snow depth gradients (associated with a higher spatial standard deviation) with clear distinctions between low snow depths over thin sea ice zones (e.g: Laptev sea region) and higher snow depths over region of thicker sea ice (e.g: Queen Elizabeth island region). Except in the MYI zones, AMSR2B data are quite smooth and characterised by a weak variability compared to that of the two altimetric products. Indeed, the statistical results which are presented in Appendix (Table A1) show that the two Ka-Ku products (ASD and DuST) are in good agreement in terms of spatial variability and the magnitude of their annual cycle considering the entire set of data over the six winter months. Note, that DuST presents the highest climatic mean solution, even higher than W99m (see also Fig. 2). In addition, DuST and ASD spatial distributions are comparable, showcasing that the difference between the two Ka-Ku altimetric products is likely a bias resulting from the re-calibration of the DusT data with OIB (this point will also be discussed in the next sections). This underlines the consistency of this methodology used to compute bi-frequency snow depth estimations in the absence of external data (ASD), since DuST is limited by the spatial availability of OIB.

Fig. 4 compare the ASD snow depth estimations with the outputs of three sea ice models in the Arctic (NESOSIM, MERCATOR and PIOMAS). The statistical diagnosis presented in Sect. 4.1 are used. They are summarised in Table A1. Amongst the three models, the MERCATOR model provides lower snow depth estimations throughout with a climatic mean of $7.4 \mathrm{~cm}$ and lower mean inter-annual and annual variability of about $3 \mathrm{~cm}$. On the contrary, climatic means of PIOMAS and NESOSIM are comparable both in terms of spatial distribution and global mean (with values of respectively $15.5 \mathrm{~cm}$ and $16.2 \mathrm{~cm}$ ). Considering annual and inter-annual variability, PIOMAS presents high values that are more evenly spread. In contrast, NESOSIM is characterised by lower values everywhere except in the Greenland and the Kara Seas.

In spite of some comparable large scale spatial patterns, these results highlight the large deviations between the ASD data and the model solutions. One striking feature is the transport of MYI along the Canadian coast by the Beaufort Gyre (see 
https://doi.org/10.5194/tc-2021-79

Preprint. Discussion started: 13 April 2021

(c) Author(s) 2021. CC BY 4.0 License.
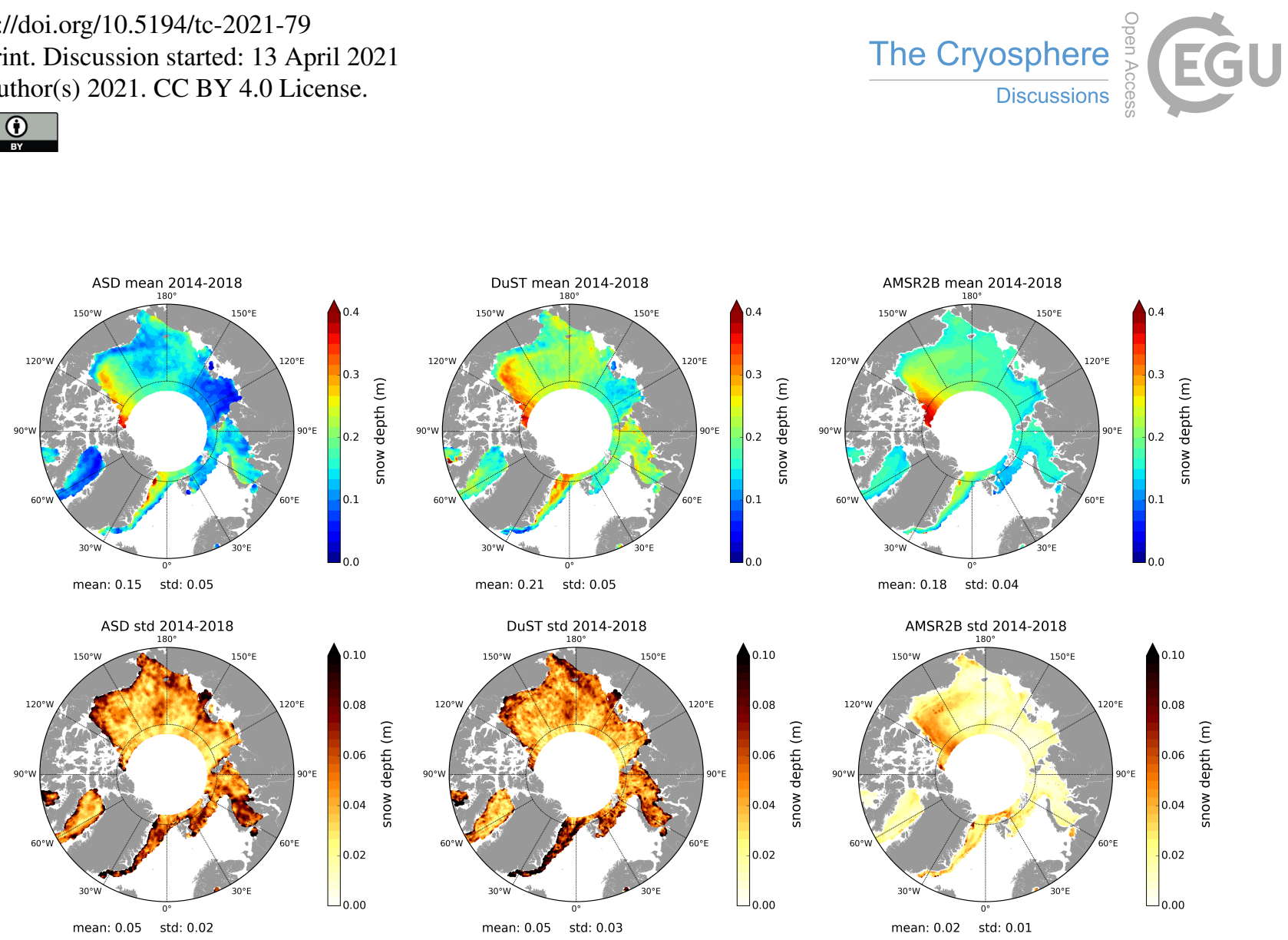

Figure 3. Comparisons of satellite snow depth estimations in the Arctic. (Top) Bi-monthly March and April "climatological" snow depth mean maps calculated over the period 2014-2018 for the ASD data (left), the DuST data (center) and the AMSR2B data (right). (Bottom) the standard deviation between all the data used to calculate the mean snow depth maps (equivalent to the Mean Inter-annual Variability computed with March and April over the same 2014-2018 time period).

also Fig. 1), which is nearly non-existent in model solutions. The patterns of deep snow over MYI are well represented in the models, but do not extend along the Canadian coastline towards the Beaufort Sea, as is the case for ASD. Overall, the models tend to overestimate snow depths nearly everywhere compared to the ASD data. The ASD data climatic mean is lower (12.3 $\mathrm{cm}$ ) and zones of thin snow layers (e.g., around $120^{\circ} \mathrm{E}$ ) are less pronounced in models (except by MERCATOR, where the snow depth is low everywhere). Models also present higher variability. However, in all data sets the maximum of variability occurs between $0^{\circ}$ and $90^{\circ} \mathrm{E}$ which is relevant because of the proximity to the open ocean and the existence of strong meteorological events (e.g Semenov et al. (2019); Dong et al. (2019)). Although investigating which causes these discrepancies is beyond the scope of this article, the strong sensitivity of the models to the reanalysis snowfall forcing data (e.g Boisvert et al. (2018); Petty et al. (2018)) could play a predominant role here.

\subsubsection{Results in Antarctica}

ASD is the only publicly available altimetric snow depth product in Antarctica. One major advantage compared to the Arctic, is that the SARAL orbit does not affect the data coverage since all the Antarctic sea ice is below $81.5^{\circ} \mathrm{S}$. Similarly to what 
https://doi.org/10.5194/tc-2021-79

Preprint. Discussion started: 13 April 2021

(c) Author(s) 2021. CC BY 4.0 License.
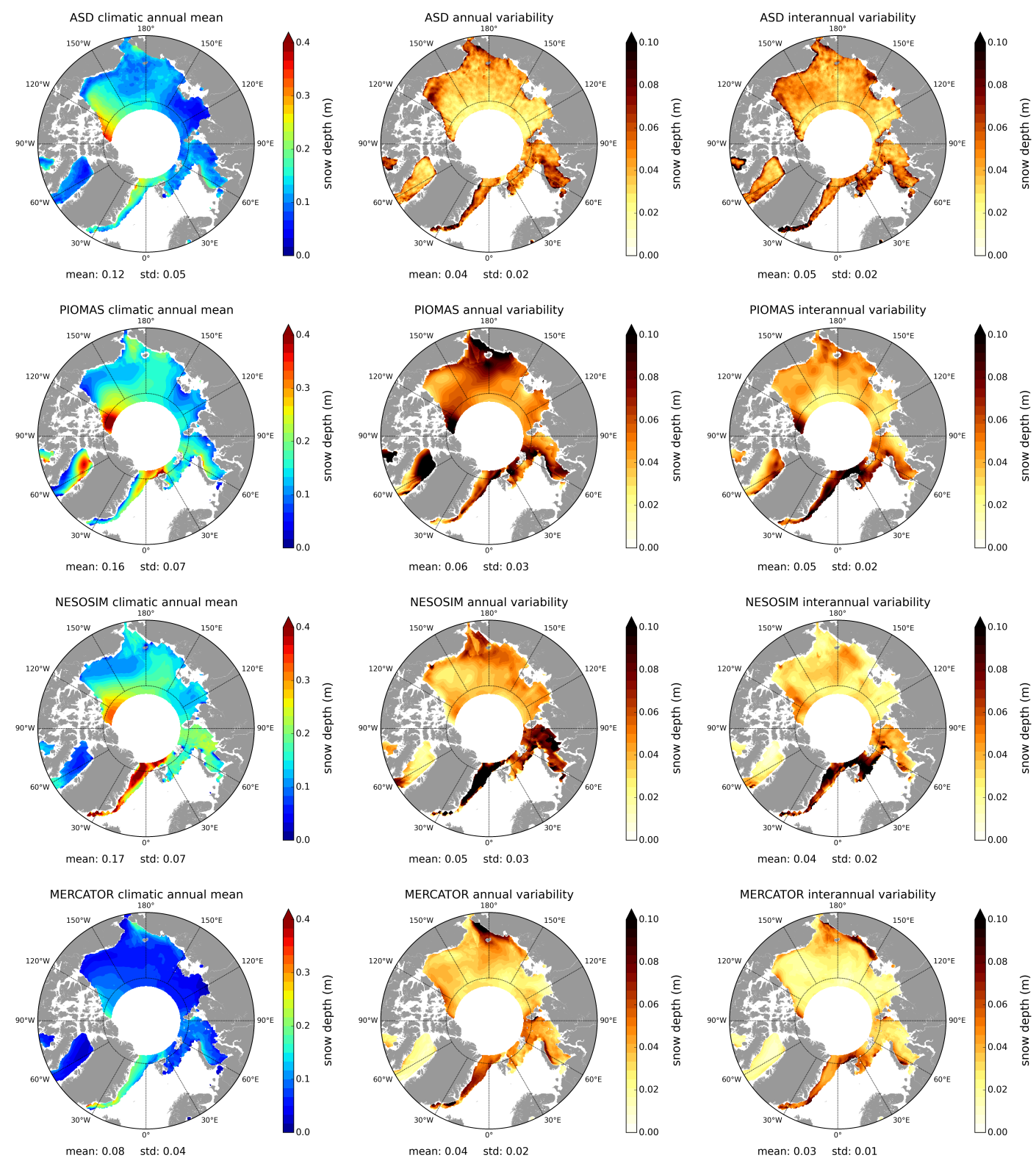

Figure 4. Comparisons between the ASD data and model snow depth products (PIOMAS, NESOSIM, MERCATOR) in the Arctic. The first column presents the "climatic mean" snow depth maps, the second column the "annual variability" and the third column the "interannual variability" as presented in Sect. 4.1. These diagnosis are calculated from March 2013 to April 2019 for ASD (first row), PIOMAS (second row) and MERCATOR (fourth row) and from March 2013 to April 2017 for NESOSIM (third row).

has been done in the previous section for the Arctic, Fig. 5 compare ASD with the AMSR2-NSIDC data and the GIOMAS (equivalent to PIOMAS but for Antarctica) and the MERCATOR sea ice model. The statistics are summarised in Table A2. 
https://doi.org/10.5194/tc-2021-79

Preprint. Discussion started: 13 April 2021

(c) Author(s) 2021. CC BY 4.0 License.

\section{(c) (i)}

In spite of a comparable climatic mean and some coherent spatial distributions such as the transport of snow in the Weddell gyre, ASD and AMSR2-NSIDC data show significant discrepancies. Unlike what we have observed in the Arctic, ASD data are relatively smooth with a weak spatial variability. In comparison, AMSR2-NSIDC data are characterised by strong contrasts between large snow depth patterns in the Weddell sea and to a less extent in the western part (from $150^{\circ} \mathrm{E}$ to $90^{\circ} \mathrm{W}$ ) and areas with nearly no snow (east side, between $0^{\circ} \mathrm{E}$ and $150^{\circ} \mathrm{E}$ ). As in the Arctic, AMSR2-NSIDC annual and inter-annual variability are weaker and much more localised than in the ASD data. One relevant difference between these two data is the systematic decrease of snow depth in October in the AMSR2-NSIDC data (see Table A2). With a climatic spatial mean of about $34.6 \mathrm{~cm}$, GIOMAS simulates everywhere very high snow depths compare to the other solutions. Considering what is provided in the literature (e.g., Worby et al., 2011), these values clearly seem to be overestimated. In the exception of the Weddell Sea, the Mercator model and ASD present comparable snow patterns with substantial coastal values not seen in the AMSR2-NSIDC data. However, the MERCATOR model displays thicker snow everywhere but in the Weddell sea. The presence of deeper snow is a well observed feature in the Weddell Sea, which is supported by ASD (e.g., Massom et al., 1997; Eicken et al., 1994).

\subsection{Comparison with in situ and airborne data}

\subsubsection{OIB}

OIB data are compared to all the data sets presented in the previous sections. We only consider OIB observations below $81.5^{\circ}$ $\mathrm{N}$ between the 2014-2018 campaigns. Fig. 6 shows an example the $29^{\text {th }}$ March 2015 track and Fig. 7 presents scatter plots comparing with the OIB data over the entire 2014-2018 time period (including all spring OIB campaigns within this period). Statistical results are summarised in Table 1.

One striking feature is the good consistency between ASD and OIB in terms of magnitude and spatial variability. The OIB data are nearly always included within the ASD envelope of uncertainties (in shaded red). These consistencies between OIB and ASD data are also demonstrated in several other OIB tracks provided in the supplementary material (Figs. S14 to S17). The DuST Ka/Ku data present an along-track variability similar to ASD, but tend to always overestimate the snow depth compared to OIB. This reinforces the hypothesis that the main difference between ASD and DuST is a bias. The AMSR2B data also reproduce the large scale snow depth variability quite well but overestimate OIB with a level comparable with DuST. The DuST and AMSR2B overestimations are quite consistent with Kwok et al. (2017), who found that this OIB product tend to have thinner snow than the NOAA Wavelet Airborne Snow Radar data set, which has been used for re-calibrations. In fact, it is important to be aware that various OIB datasets have been produced, leading to a variety of snow estimations that can reach $7 \mathrm{~cm}$ on FYI and $12 \mathrm{~cm}$ on MYI Kwok et al. (2017).

Models hardly represent the along-track variability and do not reproduce small scale patterns. A too coarse resolution could partly explain this feature. As expected, the MERCATOR model snow thickness are far below the others, whereas he PIOMAS and NESOSIM solutions provide comparable results (see also Table 1). As expected, the W99m climatology strongly overestimates snow depths and is clearly a less optimal solution. 
https://doi.org/10.5194/tc-2021-79

Preprint. Discussion started: 13 April 2021

(c) Author(s) 2021. CC BY 4.0 License.
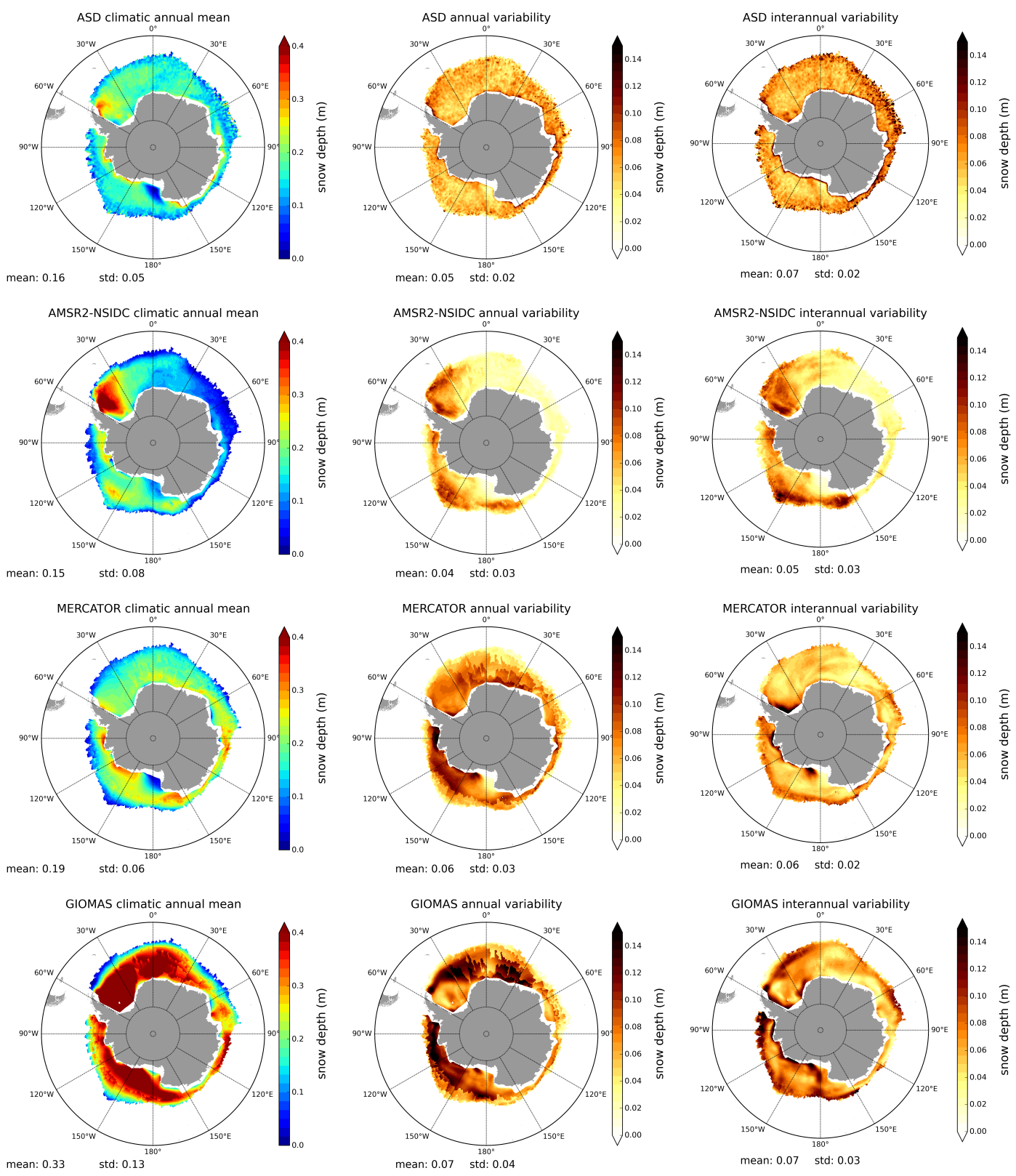

Figure 5. Comparisons between ASD data and other snow depth estimations in Antarctica (AMSR2-NSIDC, MERCATOR, GIOMAS). The first column presents the "climatic mean" snow depth maps, the second column the "annual variability" and the third column the "interannual variability" as presented in Sect. 4.1. These diagnosis are calculated from May 2013 to October 2019 for the ASD data (first row), the AMSR-2 NSIDC (second row) and the MERCATOR model (third row) and from May 2013 to October 2016 for the GIOMAS model data (fourth row). 
https://doi.org/10.5194/tc-2021-79

Preprint. Discussion started: 13 April 2021

(c) Author(s) 2021. CC BY 4.0 License.

(c) (i)
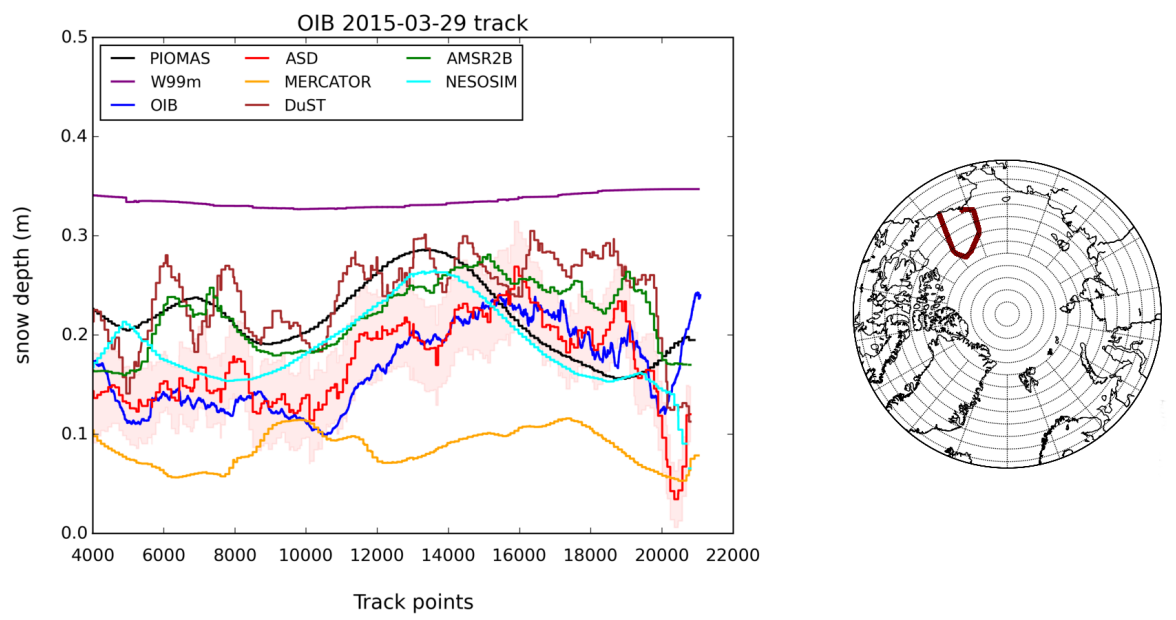

Figure 6. Along-track comparison between the snow depth products and the OIB snow radar data during $29^{\text {th }}$ March 20152015 spring campaign) in the Arctic. The red envelope refers to the ASD uncertainties. The geographical map specifies the geographical location of this particular one-day OIB track.

\begin{tabular}{|c|c|c|c|c|c|c|c|c|}
\hline & OIB & ASD & DuST & PIOMAS & MERCATOR & NESOSIM & W99m & AMSR2B \\
\hline mean $(\mathrm{cm})$ & 18.6 & 18.5 & 24.8 & 22.9 & 11.5 & 21.1 & 33.9 & 22.6 \\
\hline STD $(\mathrm{cm})$ & 7.5 & 6.9 & 6.5 & 10.4 & 4.4 & 8.5 & 1.5 & 5.8 \\
\hline mean bias $(\mathrm{cm})$ & - & $\approx 0.0$ & -6.2 & -4.3 & 7.1 & -2.6 & -15.03 & -4.0 \\
\hline RMSE $(\mathrm{cm})$ & - & 5.9 & 8.7 & 10.2 & 9.8 & 8.4 & 17.0 & 7.1 \\
\hline $\mathrm{R}$ & - & 0.66 & 0.62 & 0.50 & 0.45 & 0.51 & 0.16 & 0.63 \\
\hline
\end{tabular}

Table 1. Statistics of the comparison between OIB snow radar data and the various snow depth products considering the OIB spring campaigns of 2014-2018.

\subsubsection{IMB}

The comparison between the snow depth estimations and the IMB data for the winters 2013-2014, 2014-2015 and 2015-2016 is presented in Fig. 8. Statistical results are summarised in Table 2. Except for AMSR2B, which is only available for the months of March and April, all comparisons are performed using the exact same spatial coverage considering only data below $81.5^{\circ} \mathrm{N}$. Note that only very limited IMB data are available south of $81.5^{\circ} \mathrm{N}$ for the winter 2015-2016.

Fig. 8 and Table 2 show how the satellite mean values are closer to the in-situ observations than the model. However, the seasonal changes in the IMBs are not well reproduced by the satellite products or the models. This could reflect sampling differences as the IMB observations consist of hourly localised data, that are not representative of the wider averages of the gridded satellite or model products. DuST and ASD along-track variability are once again very similar with DuST being overall higher, highlighting the very likely bias between these two products. 
https://doi.org/10.5194/tc-2021-79

Preprint. Discussion started: 13 April 2021

(c) Author(s) 2021. CC BY 4.0 License.

(c) (i)
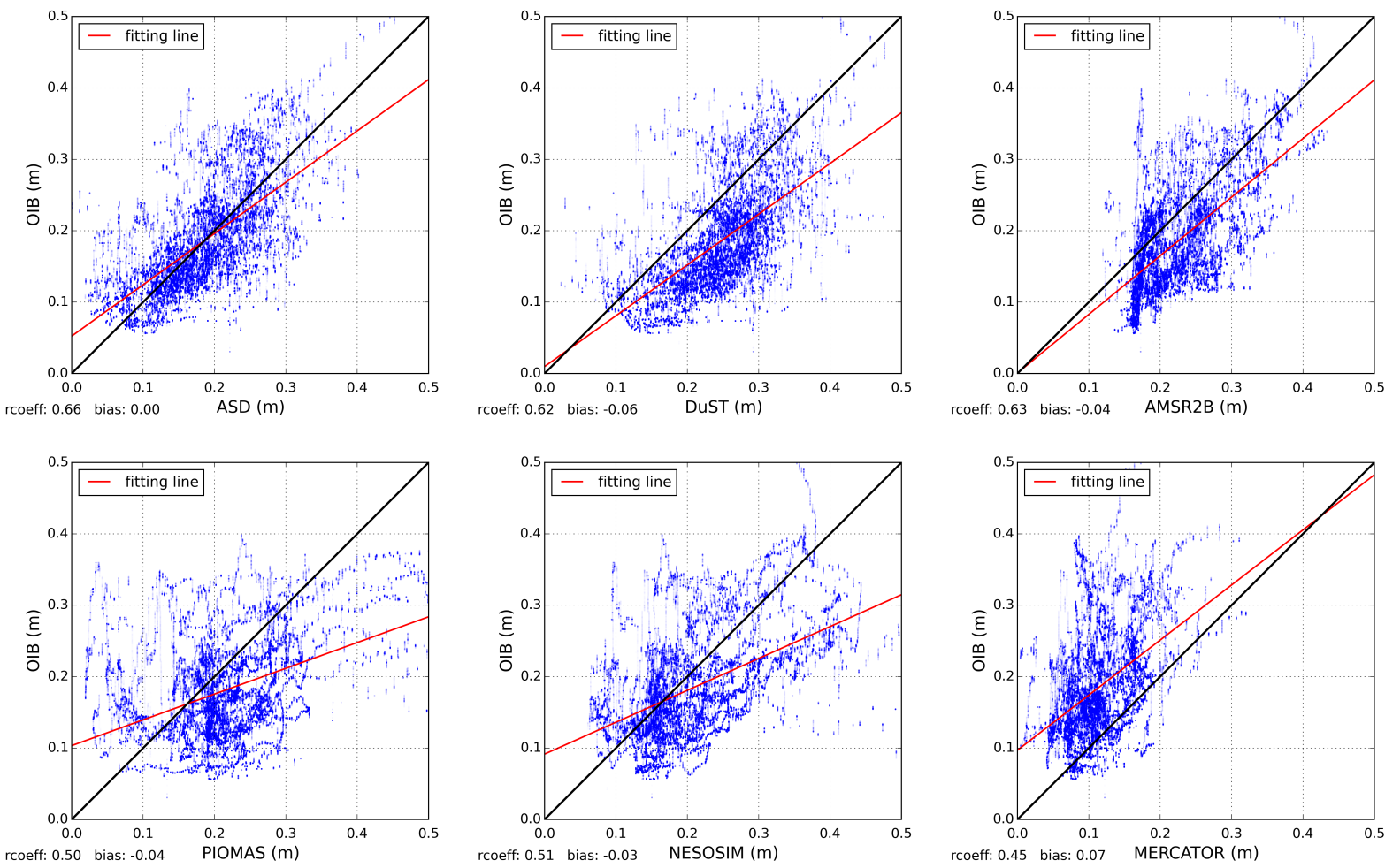

Figure 7. Scatter plots between the snow depth products and OIB snow radar data considering the 2014 to 2018 missions. For NESOSIM, 2018 is not considered.

\begin{tabular}{|c|c|c|c|c|c|c|c|c|}
\hline & IMB & ASD & DuST & PIOMAS & MERCATOR & NSIM & W99m & AMSR2B \\
\hline Mean $(\mathrm{cm})$ & 21.6 & 19.14 & 25.51 & 19.37 & 7.61 & 18.32 & 28.03 & 24.88 \\
\hline STD $(\mathrm{cm})$ & 2.2 & 3.17 & 2.90 & 4.68 & 2.17 & 3.68 & 5.16 & 1.05 \\
\hline RMSE $(\mathrm{cm})$ & - & 4.73 & 5.50 & 5.11 & 14.32 & 4.96 & 8.2 & 3.71 \\
\hline
\end{tabular}

Table 2. Statistics of the comparison with IMB data and the various snow depth products considering data acquired during 2013-2016..

\subsubsection{CryoVEx}

Fig. 9 presents the snow depth products projected along the CryoVEx flight track measured on the 31 March 2017. This figure gathers the CryoVEx snow depth estimations calculated from (a) the difference between the Ku band ASIRAS radar freeboard and the ALS laser (ALS-ASR) total freeboard, and (b) from the Ku band ASIRAS radar freeboard and the Karen (Ka-ASR) total freeboard. Note that because of SARAL spatial coverage limitation (latitude $<81.5^{\circ}$ ) and the absence of the SARIN mode in the CS-2 ESA Baseline B GOP product (used to construct the ASD data, see Sect. 2), only the track of the 31 March 2017 CryoVEx survey of the Baffin Bay can be compared with the ASD data. 
https://doi.org/10.5194/tc-2021-79

Preprint. Discussion started: 13 April 2021

(c) Author(s) 2021. CC BY 4.0 License.

\section{(c) (1)}
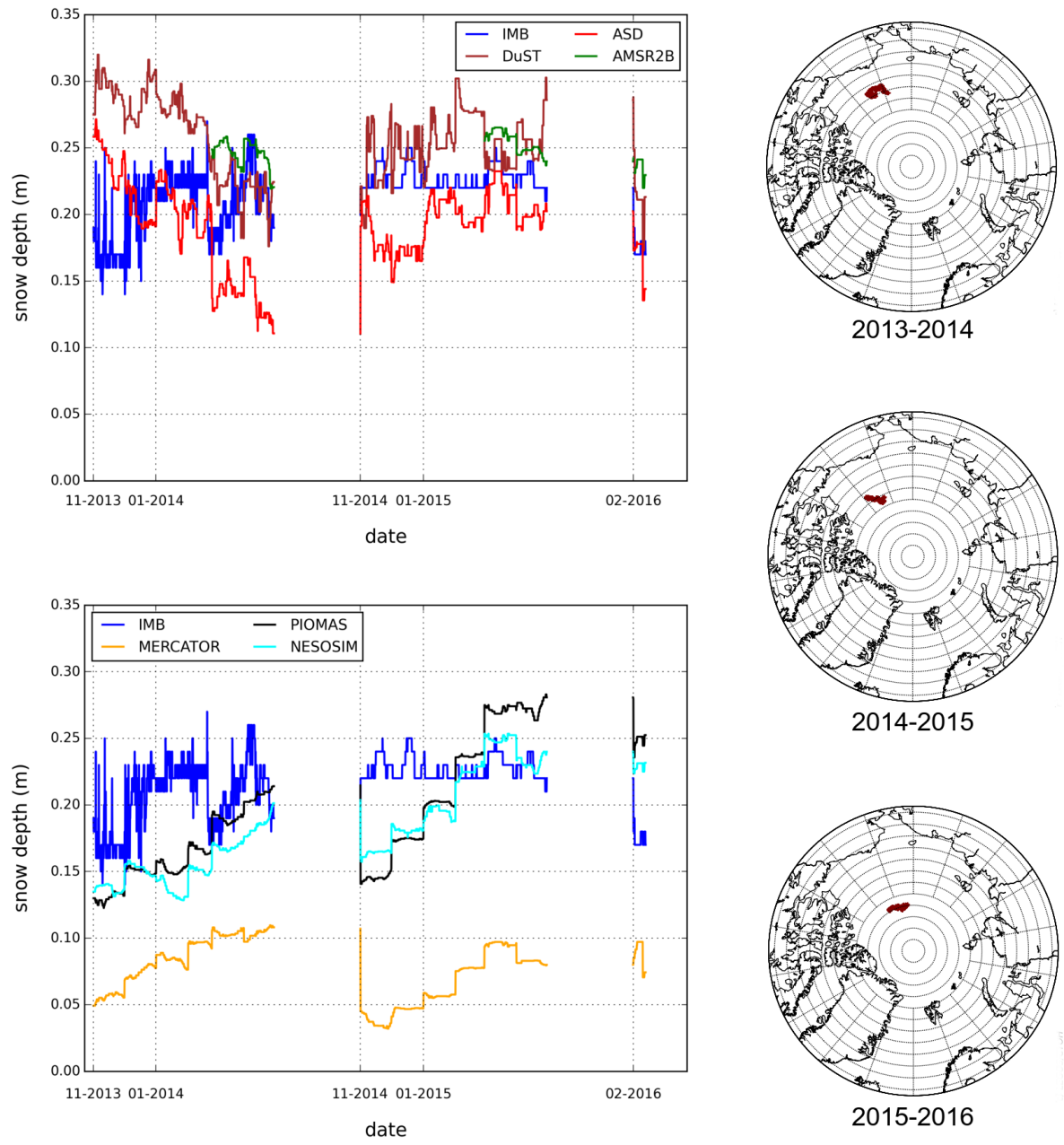

Figure 8. Along-track comparison between the snow depth products and the IMB in-situ data. (Top left) IMB buoys compared with satellite data; both passive and active, (bottom left) IMB buoys compared with model data. Right column shows geographical maps from data for all three periods (2013-2014, 2014-2015, 2015-2016). The maps presents the geographical location of the three IMB buoys.

Ka-ASR estimation exhibits very thin snow thickness. Although it might be expected in this area, this solution still contains unrealistic negative values due to the fact that ASIRAS and KAREN freeboards are nearly equivalent over FYI (without negative values). The main difference between the laser and the Ka band radar snow depth estimations seems to be a bias. Except around $71.3^{\circ} \mathrm{N}$, where a specific event may have occurred. Here, the ASD snow product tracks the magnitude of the CryoVEx airborne data with ALS-ASR and KAREN-ASR acting respectively as an upper and lower bound and within ASD range of uncertainty (in pink shading). However, the along-track variability is not well reproduced by any dataset. The MERCATOR and NESOSIM models also show similar magnitudes as the CryoVEx snow depth estimations (ALS-ASR and 

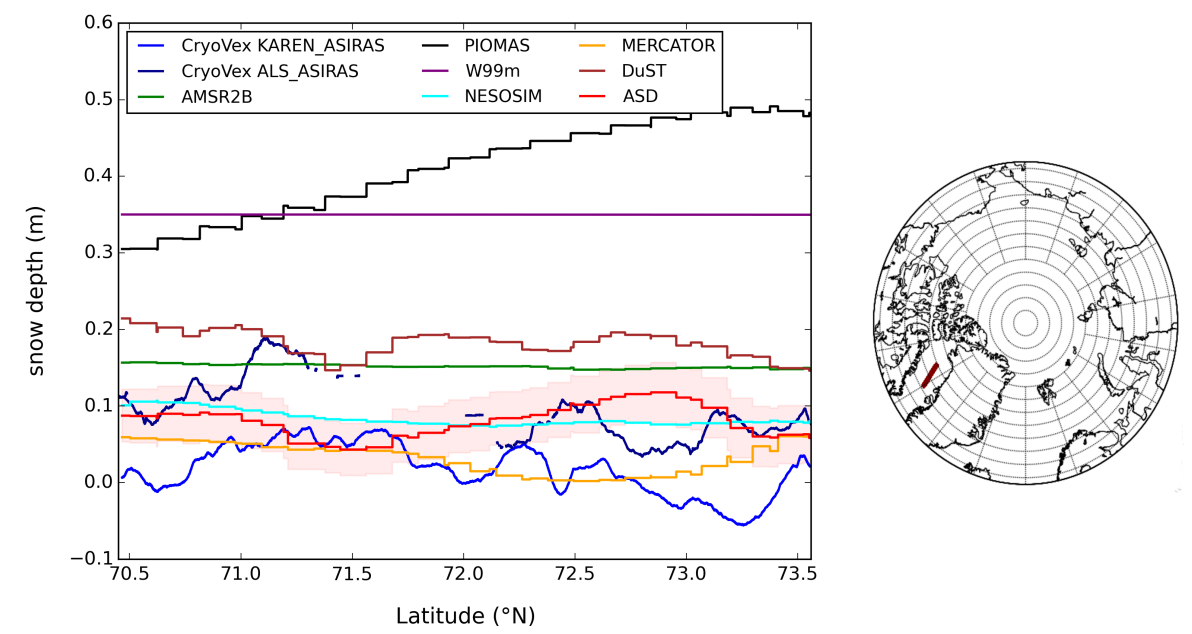

Figure 9. Along-track comparison, in the Arctic, between the snow depth products (models and satellites) and the CryoVEx snow depth data calculated from the KAREN Ka band radar (blue) and the ALS laser (dark blue) with the ASIRAS Ku-band radar during the $31^{\text {st }}$ March 2017 campaign. The map specifies the geographical location of the CryoVEx track.

Ka-ASR), while PIOMAS and the W99m climatology clearly overestimate. AMSR2B and DuST nearly always overestimate the snow depth, while The DuST along-track variability is comparable to ASD.

\section{Towards an ASD snow depth climatology}

In spite of the good results of the ASD data highlighted in the previous sections, the temporal coverage (only after 2013) remains an important limitation to the use of these data. Considering the low inter-annual snow precipitation variability compared to that of the spatial variability (e.g Figs. 2 and 4), one solution to this limitation would be to develop an ASD climatology. For that purpose, we have constructed a preliminary altimetric snow depth climatology by averaging all the ASD snow depth maps of each month during the 2013-2019 period (designated as the ASD-clim). To demonstrate the relevance of such a climatology for the years prior to 2013, the ASD-clim data are projected on all the tracks of the four OIB missions occurring between 2009 and 2012, and presented in Fig. 10.

Fig. 10 shows that the ASD climatology would be a more optimal solution than W99m, at least for the CS-2 time period.

This is highlighted with the lower bias (-0.1 m compared with -0.14), the higher correlation coefficients ( 0.71 compared with 0.06), and the lower RMSE (0.06 m compared with $0.17 \mathrm{~m}$ ) . Furthermore, even as a climatology, we obtained a correlation between the ASD-clim and OIB of the same order of magnitude as obtained in Fig. 7 with the ASD data. However, as future work, a more refined computation should be investigated. In particular, an important point would be to provide a relevant snow product for the years of Envisat. Since the Warren W99m can be considered as relatively consistent until the year of 2000, a 

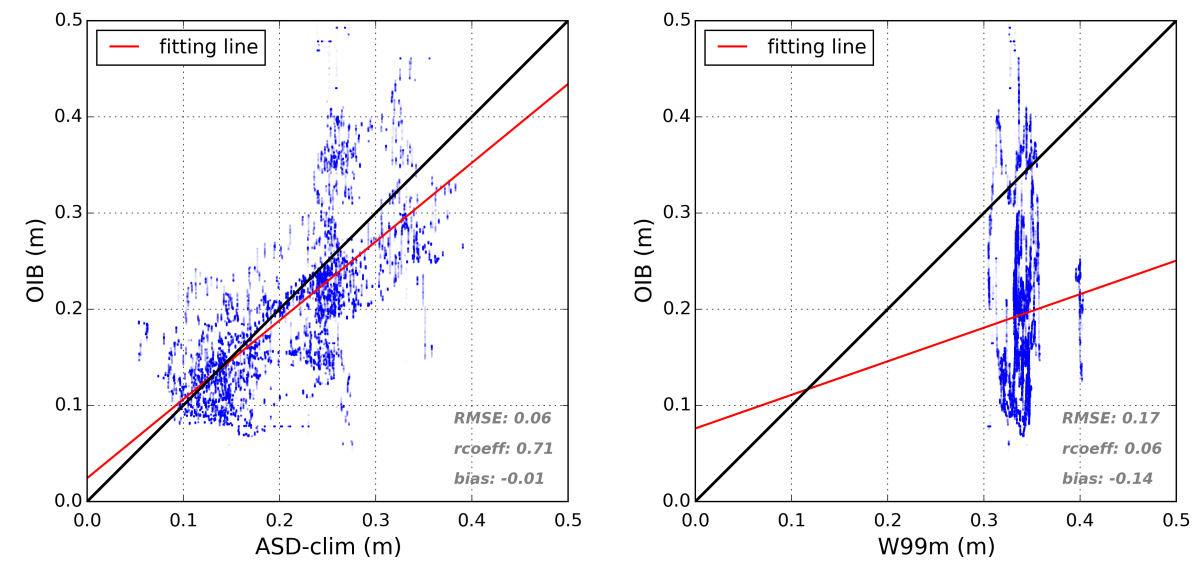

Figure 10. Scatterplots comparing the ASD and the Warren W99m climatologies considering all the tracks of 2009,2010,2011 and 2012 OIB missions.

mixed ASD-W99m product, including for instance a time dependency could be considered. Also, it could be relevant to take into account the sea ice type inter-annual variability as it is done for W99m.

Another critical point of the ASD data (for instance for sea ice volume estimations) is the reduced spatial coverage due to the SARAL orbit. While during the time period of Envisat, this does not become an issue since its orbit is equivalent to that of SARAL, the absence of data north of $81.5^{\circ} \mathrm{N}$ is a major limitation to SIT estimations. A combination of ASD with W99m and/or model data could be done to extrapolate the data. Potentially, one could also investigate a combination of ASD with W99m and/or models to extrapolate the data. In Antarctica, we do not encounter the same issue since the orbit does not reduce the spatial coverage and FYI is generally considered to be the only sea ice type present in the Southern Ocean. Then, such a climatology would be a solution to compute SIT estimations over the Envisat/CS-2 time period provided that the temporal variability of precipitations are investigated. Note, that experimental SIT estimations have already been done in Antarctica in the framework of the Sea Ice Climate Change Initiative (SI-CCI). These data used a snow climatology elaborated from AMSR-E and AMSR-2 data in a nearly equivalent manner to what has been presented here.

\section{Impacts of snow depth on SIT estimation}

Since there is still no validated freeboard product in Antarctica, this analysis has only been performed in the Arctic. From the CS-2 radar freeboard product presented in Guerreiro et al. (2017), extended to 2019, we have computed SIT estimates using the various snow depth data sets presented in this study. It is calculated from the CS-2 L1b ESA Baseline C SAR 


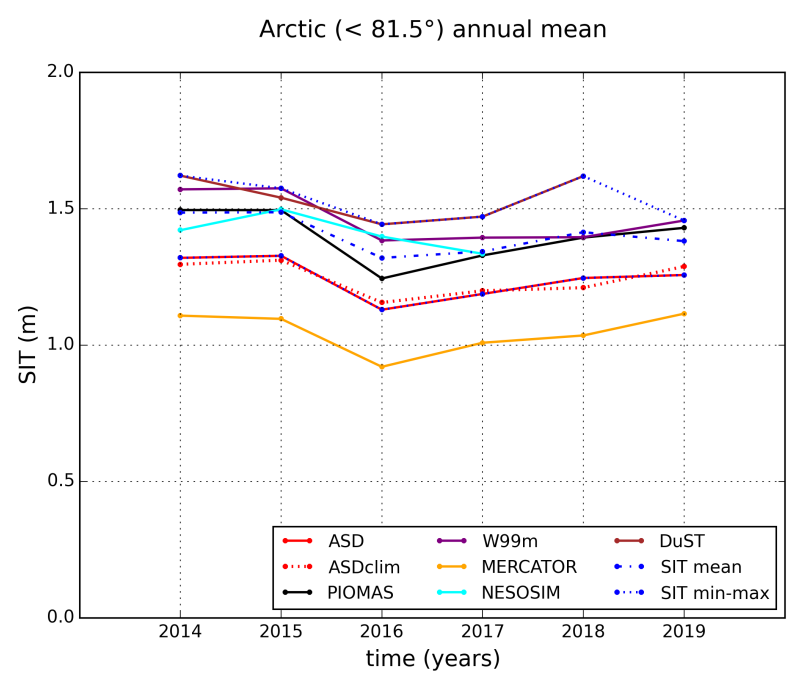

Figure 11. Arctic annual mean time series (2014-2019) of the averaged SIT solutions computed using various snow depth products (models, and active/passive satellite-based). Spatial coverage is defined by the smallest sea ice extent. The dotted blue lines define the annual mean, minimum and maximum values between all solutions (except for MERCATOR). The AMSR-2 data are not represented since they are not available over the period.

waveforms (Bouffard et al., 2018b) with the methodology presented in Sect. 2. Freeboard heights are converted into SIT assuming hydrostatic equilibrium between the snow covered sea ice and the ocean (Eq. (8))

$S I T=\frac{\rho_{w} f b_{i c e}+\rho_{s} s d}{\rho_{w}-\rho_{i}}$

The sea water density $\left(\rho_{w}\right)$ is set to $1024 \mathrm{~kg} / \mathrm{m}^{3}$, the snow density $\left(\rho_{s}\right)$ to $300 \mathrm{~kg} / \mathrm{m}^{3}$ and the sea ice density $\left(\rho_{i}\right)$ to 882 $\mathrm{kg} / \mathrm{m}^{3}$ for MYI and $917 \mathrm{~kg} / \mathrm{m}^{3}$ for FYI. Distinction between FYI and MYI follows the EUMETSAT OSI SAF sea ice type classification. The sea ice freeboard $f b_{i c e}$ is calculated from the radar freeboards, taking into account the radar speed velocity decreasing which depends on the snow depth data $s d$ following Eq. (3). SIT monthly maps are calculated for each snow depth product presented in previous sections. These monthly maps are provided for the winter of 2015 in the supplementary material (Figs. S18 to S24). Fig. 11 presents the annual mean time series of the spatial mean of all these SIT solutions (except for 435 AMSR2B which is only calculated in March and April).

Except for the MERCATOR model (which has shown to be overall significantly lower), using the ASD data provide the lowest global mean SIT estimations. Highest SIT estimations are obtained with the DuST product (and W99m), highlighting the impact of the bias previously identified between these two solutions (ASD and DuST). Considering the various snow products together (except for the MERCATOR model), the spatial mean SIT annual mean values are comprised between 1.2 $\mathrm{m}$ and $1.6 \mathrm{~m}$. This leads to a global SIT ensemble mean of $1.4 \mathrm{~m}$ (mean of the dotted blue line in Fig. 11) associated with a mean maximum deviation of $29 \mathrm{~cm}$ (mean of differences between the maximum and minimum blue dotted lines). This mean 
maximum deviation, which is approximately the mean difference between ASD and DuST, represents about 20\% of the mean SIT. Considering the good consistency between ASD and the validation snow depth data (demonstrated in Sect. 4.3), actual SIT products computed using W99m should tend to significantly overestimate Arctic sea ice volume. For instance, taking a deviation of about $0.3 \mathrm{~m}(\approx$ the mean deviation between ASD and W99m in 2015) and a mean Arctic sea ice extent of 13 millions of $\mathrm{km}^{2}$ (approximately the mean sea ice extent of 2015), the resulting SIT overestimation would lead to an sea ice volume excess of about $4.10^{3} \mathrm{~km}^{3}$, which represents about $3.5 \times 10^{15}$ litres of freshwater. Such an uncertainty is not negligible compared to the $8000 \pm 2000 \mathrm{~km}^{3}$ change in the Western Arctic freshwater content between 1995-1996 and 2009-2010 relayed in Giles et al. (2012). To give an illustrating example, this uncertainty of $3 \cdot 5 \cdot 10^{15}$ litres of freshwater would be roughly equivalent to six months of the Amazon water discharge (considering a debit of about $2.10^{8}$ litres/seconds). Deviations of only a few centimetres of the snow depth $(\approx 6 \mathrm{~cm}$ of mean deviation between ASD and W99m snow depths in 2015, see Fig. 1) have strong impacts on the freshwater budget.

Although this provides a relevant overview, such large scale global means do not show the spatial and temporal variability of the various SIT solutions. For instance, while DuST and W99m provide comparable SIT global mean estimations, the spatial and temporal information included in these two data sets are very different (e.g. Fig. 2 and 3). To better characterise the impacts of the snow depth on SIT, we propose to consider the deviations between these SIT estimates for each month of each year and at each grid point. Such an ensemble of SIT solutions will allow to characterise the level of uncertainty due to discrepancies between the different snow depths. For the month $m$ of year $y$, the standard deviation $\left(s t d_{y, m}(S I T)\right)$ and the maximum deviation $\operatorname{maxdev}_{y, m}(S I T)$ maps are calculated with Eqs.(9) and (10). $S I T_{y, m, p}$ is the SIT solution provided by the snow product $p$ and $\overline{S I T_{y, m}}$ is the mean map between all these SIT estimations. $N_{p}$ is the number of snow depth products. $\max _{p}\left(S I T_{y, m, p}\right)$ and $\min _{p}\left(S I T_{y, m, p}\right)$ are respectively the maximum and minimum monthly maps between the SIT solution of the snow depth products.

$s t d_{y, m}(S I T)=\sqrt{\frac{1}{N_{p}} \sum_{p}\left(S I T_{y, m, p}-\overline{S I T_{y, m}}\right)^{2}}$,

$\operatorname{maxdev}_{y, m}(S I T)=\max _{p}\left(S I T_{y, m, p}\right)-\min _{p}\left(S I T_{y, m, p}\right)$.

For each winter month, inter-annual mean, minimum and maximum maps of these two statistics (standard deviation $s t d_{y, m}(S I T)$ and the maximum deviation $\left.\operatorname{maxdev}_{y, m}(S I T)\right)$ can then be computed from Eqs. 11 to 13. $N_{y}$ is the number of years.

$\overline{s t d_{m}}=\frac{1}{N_{y}} \sum_{y}\left(s t d_{y, m}(S I T)\right)$

$\overline{\operatorname{maxdev}}=\frac{1}{N_{y}} \sum_{y}$ 
https://doi.org/10.5194/tc-2021-79

Preprint. Discussion started: 13 April 2021

(c) Author(s) 2021. CC BY 4.0 License.

(c) (i)

$\left(\operatorname{maxdev}_{y, m}(S I T)\right)$

$\max \left(s t d_{m}\right)=\max _{y}\left(s t d_{y, m}(S I T)\right)$

$\min \left(s t d_{m}\right)=\min _{y}\left(s t d_{y, m}(S I T)\right)$

$\min \left(\operatorname{maxdev} v_{m}\right)=\min _{y}\left(\operatorname{maxdev}_{y, m}(S I T)\right)$

These statistics quantifies the SIT uncertainty, due only to snow depth, assuming that deviations between snow depth solutions refer to the snow depth level of uncertainty. We distinguish two cases: the case « obs snow products », which considers ASD, DuST, W99m and AMSR2B and the case « all snow products », which includes in addition the PIOMAS, MERCATOR and NESOSIM model solutions. Note, that ASD-clim is not used in calculations in order to avoid the redundancy with ASD data. For similar reasons, AMSR2-NSIDC is also not taken into account. Considering « obs snow products », Fig. 12 presents maps of the metrics presented in Eqs.(11) to (17) for April. In addition, the monthly minimum, mean and maximum maps over the period 2014-2019 are presented for April in the supplementary material (Fig. S25). All the results are summarised in Table A3 which presents, for each winter month, the spatial mean value of these maps. The spatial mean of the monthly mean SIT maps (spatial mean of $\overline{S I T_{y, m, p}}$ maps are also included.

Highest impacts on SIT are generally located in near coastal zones and at the ocean/ice transitions. In these areas, maximum standard deviation can reach up to $50 \mathrm{~cm}$ and maximum deviation to $80 \mathrm{~cm}$ when considering « obs snow products ». Due to larger differences between model and observations, in particular MERCATOR, these values are higher with « all snow products » (see Table A3). Except for these specific locations, that mostly account for maxima values, the standard deviation maps are rather uniform. This suggests that spatial mean values (presented in Table A3) are a relevant indicator.

The large deviations between minimum and maximum (standard deviation and/or maximum deviation) maps indicate significant variations of the SIT level uncertainty due to snow depth from one year to an other. On the contrary, spatial mean standard deviations do not vary significantly in between months. Considering « obs snow products » and all winter months, we obtained a mean spatially averaged SIT mean standard deviation of $\approx 20 \mathrm{~cm}(14 \%) \pm 11 \mathrm{~cm}(31-9 \mathrm{~cm}$ interval, see Table A3) and mean maximum deviation of $\approx 49 \mathrm{~cm}(35 \%) \pm 25 \mathrm{~cm}$. These values increase to $\approx 27 \mathrm{~cm}(20 \%) \pm 9 \mathrm{~cm}$ for the standard deviation and $\approx 76 \mathrm{~cm}(58 \%) \pm 25 \mathrm{~cm}$ for the maximum deviation when we take into account « all snow products ». Therefore, 
https://doi.org/10.5194/tc-2021-79

Preprint. Discussion started: 13 April 2021

(c) Author(s) 2021. CC BY 4.0 License.
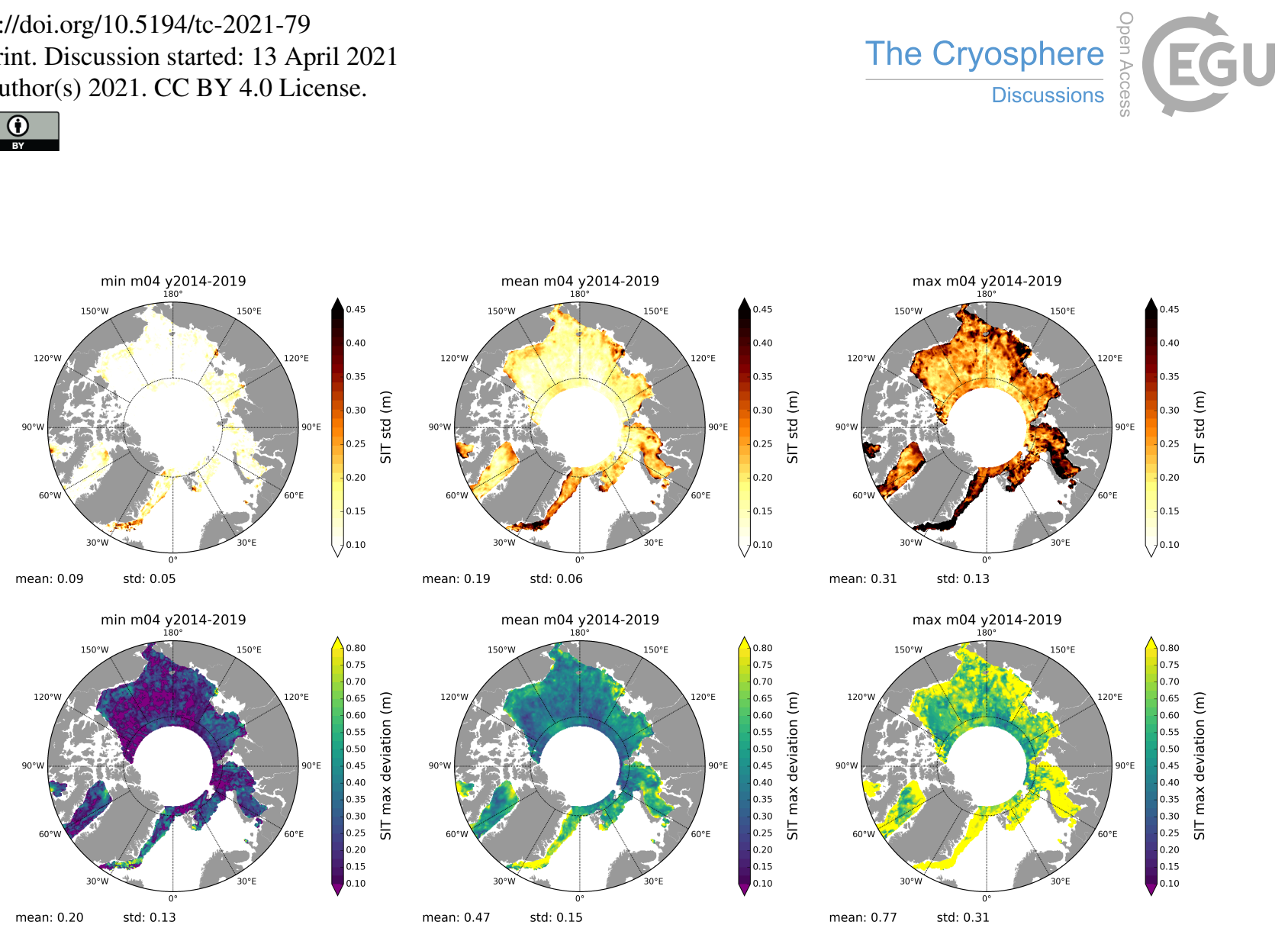

Figure 12. Inter-annual minimum $\left(\min \left(s t d_{m}\right)\right.$, second column), mean $\left(\overline{s t d_{m}}\right.$, first column) and maximum $\left(\max \left(s t d_{m}\right)\right.$, third column) maps of the standard deviation (first row) and the maximum deviation (second row) for the month of April $(m=04)$. The snow products used to compute the maps are ASD, DuST, AMSR2B and W99m. These maps correspond to the case « obs snow products ».

compared to the deviation (roughly $30 \mathrm{~cm}$ ) that can be extract from the difference between ASD (red line) and the SIT max line (dotted blue) in Fig. 11, we obtain higher maximum deviations using this methodology. It suggests, that considering large scale global means could tend to underestimate impacts of snow depth on SIT, and therefore the SIT uncertainty. Note, that in addition to a more refined methodology, taking into account AMSR2B, which can reach high values, might have a small impact here as well.

Besides providing a relevant quantification of the impacts of snow depth on SIT, such « multi-observation » approach also provide a space and time variability of uncertainties. It also avoids the necessity of relying on the strong, and usual assumption, of Gaussian propagation of de-correlated errors. These uncertainty estimates are very important for data assimilation, in which the characterisation of observation error is of main importance for constraining models (e.g., Stewart et al., 2008; Bunzel et al., 2016; Janjić et al., 2018). Note, that there are a growing number of research programs and international initiative which aims 510 at coordinating efforts for better characterising uncertainties and provide traceable quality indicators to sea ice EO products (e.g., World Meteorological Organisation (WMO) Workshop at AWI, European Union/European Commission (EU/EC) Polar week). 
https://doi.org/10.5194/tc-2021-79

Preprint. Discussion started: 13 April 2021

(c) Author(s) 2021. CC BY 4.0 License.

\section{(c) (i)}

\section{Conclusions and Discussions}

In this study, we have presented a Ka-Ku snow depth product computed, in both hemispheres, from the data obtained by altimeters on board the satellites SARAL (Ka-band) and CS-2 (Ku-band). This product has been compared over the period 2013-2019 with: the other Ka-Ku snow depth product (DuST, only in the Arctic), AMSR-2 passive radiometer snow depth estimations, W99m (only in the Arctic) and snow depth solutions of the models PIOMAS (GIOMAS in Antarctica), MERCATOR and NESOSIM (only in the Arctic). Thereafter, all these products have been evaluated, in the Arctic, against OIB airborne data, IMB snow buoys and a CryoVEx airborne campaign, which includes Ka-Ku snow depth altimetric measurements. The lack of such validation data in Antarctica remains a major obstacle to the development of SIT products. It is currently a primary focus of the ESA CSAO+ project.

We observed a good agreement between the two Ka-Ku products (ASD and DuST) in terms of spatial distributions and annual and inter-annual variability. However, DuST always exhibits higher snow depth patterns. We found that the difference between these two products is mainly a bias, of about $6.5 \pm 0.5 \mathrm{~cm}$ (see Table A1), likely due to the re-calibration of the DuST product with OIB data. The AMSR-2 data also tend to overestimate snow depths compared to ASD. This overestimation is lower than DuST, in average of about $3 \mathrm{~cm}$, and does not seem to only be a bias since AMSR2 spatial patterns present noticeable differences. We reiterate, that comparisons with AMSR-2 have only been conducted in March and April (with the AMSR2B product for the Arctic, see Sect. 3) because the data are not available over MYI for the other months. Comparisons with models have highlighted several features that distinguish the two hemispheres. In the Arctic, the MERCATOR model is always far lower the other products, and simulates limited snow depth variability. In contrast, NESOSIM and PIOMAS tend to overestimate snow depth, in average of a few centimetres, compared to ASD. We found comparable spatial representations between PIOMAS and NESOSIM although NESOSIM presents higher snow depths over MYI and higher variability. These two models hardly represent the MYI sea ice drift in the Beaufort Gyre that can be observed in satellite observations. Note that we have not considered in this study the recent SnowModel-LG model, that should better capture the Arctic snow depth over sea ice spatial variability (Stroeve et al., 2020; Liston et al., 2020). We refer to (Zhou et al., 2020a) for a comparison between the SnowModel-LG and various snow depth observation products.

In Antarctica, for satellite-bsed observations, spatial mean snow depth values of AMSR-2 and ASD are quite close. However, we found that AMSR2-NSIDC estimations are lower in zones of thin snow while it tends to strongly overestimates in areas of thicker snow compared to ASD. Regarding models, over Antarctica, the MERCATOR model simulates mean values in better agreement with ASD. However, thicker snow patterns and the clockwise drifts in the Weddell sea are not represented. The GIOMAS model simulates very high snow depths nearly everywhere, likely leading to unrealistic snow depth representations. Sea ice models are generally very dependent on atmospheric forcings and differences in snow accumulation in models can lead to very different snow depths. Model biases are largely due to the lack of consistent observations which has, so far, limited the tuning of snow parameters such as albedo or snow diffusion coefficients (Chevallier et al., 2017; Uotila et al., 2019).

In evaluation and for comparison of the snow depth products, we have compared with OIB, CryoVEx and in-situ IMB snow depths over the Arctic. Comparisons with OIB have shown satisfying consistencies with the ASD estimations. Considering 
https://doi.org/10.5194/tc-2021-79

Preprint. Discussion started: 13 April 2021

(c) Author(s) 2021. CC BY 4.0 License.

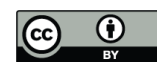

the 2013-2018 campaigns, we found a RMSE of about $6 \mathrm{~cm}$ with a correlation coefficient of 0.66. By comparison, the DuST product has a RMSE of $8.7 \mathrm{~cm}$ and AMSR2B of $7 \mathrm{~cm}$. Note that this higher RMSE for DuST, in spite of a re-calibration, probably comes from the OIB version used for re-calibrating. Indeed, DuST is re-calibrated against the OIB NOAA Wavelet Airborne Snow Radar data set which is expected to present higher snow depth values. The various snow depth products are less consistent when comparing with IMB, although ASD mean values present consistent order of magnitude. Due to the data coverage, validation with CryoVEx has been limited to one single track (where both Ku-band radar (ASIRAS), Ka-band radar (KAREN) and lidar scanner (ALS) were available). We observed, that KAREN-ASIRAS snow depth estimations are low, including a non-negligible amount of negative values. A more refined analysis would need to be done to assess these snow depth data. However, ASD data always remains in between the laser-Ku (ALS-ASR) and Ka-Ku (Ka-ASR) CryoVEx snow depth estimations. Since the results of such comparisons with validation data can vary from one methodology to another (e.g., grid sizes, smoothing kernel, data set versions, etc...), they do not aim to assess the best snow depth product. However, they demonstrate how ASD provides a relevant snow depth solution, in good agreement with several validation data, and that ASD allows for characterisation the deviations between the different snow depth products.

An important limitation of the ASD snow depth data is its temporal coverage, imposed by SARAL (only from 2013). To circumvent this limitation, we have shown that a simple monthly climatology, constructed as the average of ASD snow depth maps over the 2013-2019 period, could be a relevant option. More specifically, we have demonstrated that such a climatology could provide a more reliable solution than the W99m climatology, which strongly overestimates snow depths. Indeed, comparison between the ASD climatology and the 2009-2013 OIB missions shows good consistency (comparable results of similar magnitude as when comparing the actual ASD product with OIB campaigns from 2014-2018), while W99m has a mean bias of about $14 \mathrm{~cm}$ with an associated RMSE of $17 \mathrm{~cm}$ (when comparing with OIB). Such a climatology should be refined in order to provide relevant snow depth representations for at least the Envisat/CS-2 time period. For instance, the possibility of constructing a climatology using both ASD, AMSR and W99m information could be investigated.

A better snow depth representation significantly improve SIT estimates. In this context, this study has investigated the impacts of the snow depth on SIT. Meanwhile, we have also presented a methodology to characterise the SIT level of uncertainty due to the snow depth deviations between products. The approach constructed an ensemble of SIT solutions using the different snow depth products over the 2013-2019 period. Thus, providing an estimation of the SIT level of uncertainty due to snow depth discrepancies and its space and time variability. Note, that equivalent methodologies are frequently used in multimodel approaches. Taking only into account the satellite products AMSR2B, ASD, DuST and the W99m climatology over the 2013-2019 period, we found a spatially averaged mean standard deviation of $20 \mathrm{~cm}$ (14.2\% of the global mean SIT) and mean maximum deviation of $49 \mathrm{~cm}$ (35\% of the global mean SIT) between the different SIT estimations. In some locations, deviations between SIT estimations reached up to $77 \mathrm{~cm}$ (55\% of global mean SIT).

We have highlighted in this study that the DuST and ASD products, albeit computed from data acquired by the same sensors at the same time, present some significant differences due to the methodology applied. The main difference is, that for ASD we compare LRM data (PLRM for CS-2) while DuST compares LRM data with SAR data. The advantage of comparing LRM data together is that they have comparable footprint sizes, which by difference reduces the effects of surface roughness to highlight 
https://doi.org/10.5194/tc-2021-79

Preprint. Discussion started: 13 April 2021

(c) Author(s) 2021. CC BY 4.0 License.

(c) (i)

the effects of volume backscatter and penetration. DuST, on the other hand, relies on the calibration of the measurements on OIB without taking into account effects of the surface roughness. In fact, differences in surface roughness and the effect it has on radar penetration and retrieval of surface elevation is currently one of the other main contributors to the SIT uncertainty (e.g., Hendricks et al., 2010; Ricker et al., 2014; Landy et al., 2020), which still to be further investigated. We have only considered the roughness as mainly depending on the size of the footprint, but the backscattering coefficient variability is not as trivial and depends on several snow physical properties such as density, grain size, salinity or moisture (e.g., Lundberg et al., 2006; Willatt et al., 2010; Adodo et al., 2018; Nandan et al., 2020). An analysis of these dependencies is out the scope of this study. However, we iterate that the use of two satellites, operating in different modes, with different orbits, leads to important uncertainties and differences that cannot be neglected.

The high-priority candidate mission, CRISTAL, which shall entail a dual-frequency Ka/Ku SAR altimeter could address some of these issues. The fact of having coincident and collocated SAR measurements obtained from the same platform, with similar ground footprints, for both frequencies, will enable direct comparisons and a better understanding of the relative impacts of the surface roughness, radar penetration and volume backscattering. In this context, ASD demonstrates the possibilities of dual-frequency snow depth estimations, which could be further improved using physical retracking (as opposed to empirical re-trackers which has their own limitations, e.g., Ricker et al., 2014). In addition, CRISTAL will also mitigate the issue of the spatial coverage limitation of $81.5^{\circ} \mathrm{N}$ imposed by SARAL in the Arctic. Prior to CRISTAL data, comparisons with the very recent ICESat-2/CS-2 snow depth estimations (Kwok et al., 2020) computed from the difference between laser and $\mathrm{Ku}$-band measurements certainly provides important first results. Moreover, the recent change of CS-2 orbit to align with ICESat-2 (CRYO2ICE), providing collocated measurement with $\approx 3 \mathrm{~h}$ temporal delay, also allows for investigation of Ku-band penetration and the discrepancies that different radar footprints can introduces.

Data availability. The ASD data used in this study are freely available at http://ctoh.legos.obs-mip.fr/data/sea-ice-products/sea-ice-thickness. In case of unavailability please contact the authors Florent Garnier (FG) or Sara Fleury (SF) to access the data.

Author contributions. FG and SF have conceived the study and wrote the paper. All named authors have participated to the present article within the named projects and have brought contributions to the elaboration of its final version.

Competing interests. The authors declare that they have no conflict of interest.

Acknowledgements. This research is supported by the ESA POLAR+ Snow on Sea Ice, the CryoSat+ Antarctic Ocean projects (CSAO+) and the CryoSat SciEnce-oriented data ANalysis over Sea-ICE areas (CryoSeaNICE). It has benefited from the support of the CNES TOSCA CASSIS project and the ESA living planet fellowship. The work has also been supported by the Programme Nationale de Télédétection 
https://doi.org/10.5194/tc-2021-79

Preprint. Discussion started: 13 April 2021

(C) Author(s) 2021. CC BY 4.0 License.

(c) (i)

610 Spatiale (PNTS, http://programmes.insu.cnrs.fr/pnts/), grant $\mathrm{n}^{\circ}$ PNTS-2020-11. We also thank the Center for Topographic studies of the Oceans and Hydrosphere (CTOH) at LEGOS. 
https://doi.org/10.5194/tc-2021-79

Preprint. Discussion started: 13 April 2021

(c) Author(s) 2021. CC BY 4.0 License.

(c) (i)

\section{References}

Adodo, F. I., Remy, F., and Picard, G.: Seasonal variations of the backscattering coefficient measured by radar altimeters over the Antarctic Ice Sheet, The Cryosphere, 12, 1767-1778, https://doi.org/10.5194/tc-12-1767-2018, https://tc.copernicus.org/articles/12/1767/2018/, 2018.

Andersen, O. B. and Knudsen, P.: The DTU15 Mean Sea Surface and Mean Dynamic Topography, in Oral Presentation in the 2015 OSTST Meeeting, Reston, USA, 2015.

Andreas, E. L., Jordan, R. E., and Makshtas, A. P.: Parameterizing turbulent exchange over sea ice: The Ice Station Weddell results, BoundaryLayer Meteorology, 114, 439-460, 2005.

Armitage, T. W. K. and Ridout, A. L.: Arctic sea ice freeboard from AltiKa and comparison with CryoSat2 and Operation IceBridge,

Geophysical Research Letters, 42, 6724-6731, https://doi.org/10.1002/2015GL064823, https://agupubs.onlinelibrary.wiley.com/doi/abs/ 10.1002/2015GL064823, 2015.

Bin, C., Vihma, T., Zhanhai, Z., Zhijun, L., and Huiding, W.: Snow and sea ice thermodynamics in the Arctic: Model validation and sensitivity study against SHEBA data, Advances in Polar Science, 19, 108-122, 2008.

Blanchard-Wrigglesworth, E., Farrell, S., Newman, T., and Bitz, C.: Snow cover on Arctic sea ice in observations and an Earth System Model, Geophysical Research Letters, 42, 10-342, 2015.

Blazey, B., Holland, M., and Hunke, E.: Arctic Ocean sea ice snow depth evaluation and bias sensitivity in CCSM, The Cryosphere, 7, 1887, 2013.

Boisvert, L. N., Webster, M. A., Petty, A. A., Markus, T., Bromwich, D. H., and Cullather, R. I.: Intercomparison of Precipitation Estimates over the Arctic Ocean and Its Peripheral Seas from Reanalyses, Journal of Climate, 31, 8441-8462, https://doi.org/10.1175/JCLI-D-180125.1, https://doi.org/10.1175/JCLI-D-18-0125.1, 2018.

Bouffard, J., Naeije, M., Banks, C. J., Calafat, F. M., Cipollini, P., Snaith, H. M., Webb, E., Hall, A., Mannan, R., Féménias, P., and Parrinello, T.: CryoSat ocean product quality status and future evolution, Advances in Space Research, 62, 15491563, https://doi.org/https://doi.org/10.1016/j.asr.2017.11.043, https://www.sciencedirect.com/science/article/pii/S0273117717308542, the CryoSat Satellite Altimetry Mission: Eight Years of Scientific Exploitation, 2018a.

Bouffard, J., Webb, E., Scagliola, M., Garcia-Mondéjar, A., Baker, S., Brockley, D., Gaudelli, J., Muir, A., Hall, A., Mannan, R., Roca, M., Fornari, M., Féménias, P., and Parrinello, T.: CryoSat instrument performance and ice product quality status, Advances in Space Research, 62, 1526-1548, https://doi.org/https://doi.org/10.1016/j.asr.2017.11.024, https://www.sciencedirect.com/science/article/ pii/S0273117717308359, the CryoSat Satellite Altimetry Mission: Eight Years of Scientific Exploitation, $2018 \mathrm{~b}$.

Braakmann-Folgmann, A. and Donlon, C.: Estimating snow depth on Arctic sea ice using satellite microwave radiometry and a neural network., Cryosphere, 13, 2019.

Brucker, L. and Markus, T.: Arctic-scale assessment of satellite passive microwave-derived snow depth on sea ice using Operation IceBridge airborne data, Journal of Geophysical Research: Oceans, 118, 2892-2905, 2013.

Bunzel, F., Notz, D., Baehr, J., Müller, W. A., and Fröhlich, K.: Seasonal climate forecasts significantly affected by observational uncertainty of Arctic sea ice concentration, Geophysical Research Letters, 43, 852-859, https://doi.org/https://doi.org/10.1002/2015GL066928, https: //agupubs.onlinelibrary.wiley.com/doi/abs/10.1002/2015GL066928, 2016.

Chang, A., Foster, J., and Hall, D. K.: Nimbus-7 SMMR derived global snow cover parameters, Annals of glaciology, 9, 39-44, 1987. 
https://doi.org/10.5194/tc-2021-79

Preprint. Discussion started: 13 April 2021

(c) Author(s) 2021. CC BY 4.0 License.

(c) (i)

Chevallier, M., Smith, G. C., Dupont, F., Lemieux, J.-F., Forget, G., Fujii, Y., Hernandez, F., Msadek, R., Peterson, K. A., Storto, A., et al.: Intercomparison of the Arctic sea ice cover in global ocean-sea ice reanalyses from the ORA-IP project, Climate Dynamics, 49, 11071136, 2017.

Comiso, J. C., Cavalieri, D. J., and Markus, T.: Sea ice concentration, ice temperature, and snow depth using AMSR-E data, IEEE Transactions on Geoscience and Remote Sensing, 41, 243-252, 2003.

Déry, S. J. and Tremblay, L.: Modeling the effects of wind redistribution on the snow mass budget of polar sea ice, Journal of Physical Oceanography, 34, 258-271, 2004.

Dong, C., Gao, X., Zhang, Y., Yang, J., Zhang, H., and Chao, Y.: Multiple-scale variations of sea ice and ocean circulation in the Bering Sea using remote sensing observations and numerical modeling, Remote Sensing, 11, 1484, 2019.

Eicken, H., Lange, M., and Wadhams, P.: Characteristics and distribution patterns of snow and meteoric ice in the Weddell Sea and their contribution to the mass balance of sea ice, Annales Geophysicae, 12, 80-93, 1994.

Eicken, H., Fischer, H., and Lemke, P.: Effects of the snow cover on Antarctic sea ice and potential modulation of its response to climate change, Annals of Glaciology, 21, 369-376, 1995.

Farrell, S. L., Kurtz, N., Connor, L. N., Elder, B. C., Leuschen, C., Markus, T., McAdoo, D. C., Panzer, B., Richter-Menge, J., and Sonntag, J. G.: A first assessment of IceBridge snow and ice thickness data over Arctic sea ice, IEEE Transactions on Geoscience and Remote Sensing, 50, 2098-2111, 2011.

Fichefet, T. and Maqueda, M. M.: Sensitivity of a global sea ice model to the treatment of ice thermodynamics and dynamics, Journal of Geophysical Research: Oceans, 102, 12 609-12 646, 1997.

665 Fons, S., Kurtz, N. T., Bagnardi, M., Petty, A. A., and Tilling, R.: Assessing CryoSat-2 Antarctic snow freeboard retrievals using data from ICESat-2, Earth and Space Science Open Archive, p. 23, https://doi.org/10.1002/essoar.10506473.1, 2021.

Fons, S. W. and Kurtz, N. T.: Retrieval of snow freeboard of Antarctic sea ice using waveform fitting of CryoSat-2 returns., Cryosphere, 13, 2019.

Giles, K., Laxon, S., Wingham, D., Wallis, D., Krabill, W., Leuschen, C., McAdoo, D., Manizade, S., and Raney, R.: Combined airborne laser and radar altimeter measurements over the Fram Strait in May 2002, Remote Sensing of Environment, 111, 182-194, 2007.

Giles, K. A., Laxon, S. W., Ridout, A. L., Wingham, D. J., and Bacon, S.: Western Arctic Ocean freshwater storage increased by wind-driven spin-up of the Beaufort Gyre, Nature Geoscience, 5, 194-197, 2012.

Granskog, M. A., Assmy, P., Gerland, S., Spreen, G., Steen, H., and Smedsrud, L. H.: Arctic research on thin ice: Consequences of Arctic sea ice loss, Eos Trans. AGU, 97, 22-26, 2016.

675 Grenfell, T. C. and Maykut, G. A.: The optical properties of ice and snow in the Arctic Basin, Journal of Glaciology, 18, 445-463, 1977.

Grody, N. C.: Classification of snow cover and precipitation using the Special Sensor Microwave Imager, Journal of Geophysical Research: Atmospheres, 96, 7423-7435, 1991.

Grosfeld, K., Treffeisen, R., Asseng, J., Bartsch, A., Bräuer, B., Fritzsch, B., Gerdes, R., Hendricks, S., Hiller, W., Heygster, G., et al.: Online sea-ice knowledge and data platform< www. meereisportal. de, Polarforschung, 85, 143-155, 2016.

Guerreiro, K., Fleury, S., Zakharova, E., Rémy, F., and Kouraev, A.: Potential for estimation of snow depth on Arctic sea ice from CryoSat-2 and SARAL/AltiKa missions, Remote Sensing of Environment, 186, 339-349, 2016.

Guerreiro, K., Fleury, S., Zakharova, E., Kouraev, A., Rémy, F., and Maisongrande, P.: Comparison of CryoSat-2 and ENVISAT radar freeboard over Arctic sea ice: toward an improved Envisat freeboard retrieval, The Cryosphere, 11, 2059-2073, https://doi.org/10.5194/tc11-2059-2017, https://www.the-cryosphere.net/11/2059/2017/, 2017. 
https://doi.org/10.5194/tc-2021-79

Preprint. Discussion started: 13 April 2021

(c) Author(s) 2021. CC BY 4.0 License.

(c) (i)

685 Haas, C., Haapala, J., Hanson, S., Rabenstein, L., Rinne, E., and Wilkinson, J.: CryoVEx 2006: field report, 2006.

Haas, C., Beckers, J., King, J., Silis, A., Stroeve, J., Wilkinson, J., Notenboom, B., Schweiger, A., and Hendricks, S.: Ice and snow thickness variability and change in the high Arctic Ocean observed by in situ measurements, Geophysical Research Letters, 44, $10-462,2017$.

Helm, V., Hendricks, S., Göbell, S., Rack, W., Haas, C., Nixdorf, U., and Boebel, T.: CryoVex 2004 and 2005 (BoB) data acquisition and final report, Alfred Wegener Institute, Bremerhaven, Germany., 2006.

Helm, V., Humbert, A., and Miller, H.: Elevation and elevation change of Greenland and Antarctica derived from CryoSat-2, The Cryosphere, 8, 1539-1559, 2014.

Hendricks, S., Stenseng, L., Helm, V., and Haas, C.: Effects of surface roughness on sea ice freeboard retrieval with an Airborne Ku-Band SAR radar altimeter, in: 2010 IEEE International Geoscience and Remote Sensing Symposium, pp. 3126-3129, IEEE, 2010.

Holland, D. M., Mysak, L. A., Manak, D. K., and Oberhuber, J. M.: Sensitivity study of a dynamic thermodynamic sea ice model, Journal of Geophysical Research: Oceans, 98, 2561-2586, 1993.

Ingram, W., Wilson, C., and Mitchell, J.: Modeling climate change: An assessment of sea ice and surface albedo feedbacks, Journal of Geophysical Research: Atmospheres, 94, 8609-8622, 1989.

Janjić, T., Bormann, N., Bocquet, M., Carton, J. A., Cohn, S. E., Dance, S. L., Losa, S. N., Nichols, N. K., Potthast, R., Waller, J. A., and Weston, P.: On the representation error in data assimilation, Quarterly Journal of the Royal Meteorological Society, 144, 1257-1278, https://doi.org/https://doi.org/10.1002/qj.3130, https://rmets.onlinelibrary.wiley.com/doi/abs/10.1002/qj.3130, 2018.

Kacimi, S. and Kwok, R.: The Antarctic sea ice cover from ICESat-2 and CryoSat-2: freeboard, snow depth, and ice thickness, The Cryosphere, 14, 4453-4474, https://doi.org/10.5194/tc-14-4453-2020, 2020.

Kaminski, T., Kauker, F., Toudal Pedersen, L., Voßbeck, M., Haak, H., Niederdrenk, L., Hendricks, S., Ricker, R., Karcher, M., Eicken, H., et al.: Arctic mission benefit analysis: impact of sea ice thickness, freeboard, and snow depth products on sea ice forecast performance, The Cryosphere, 12, 2569-2594, 2018.

Kelly, R.: The AMSR-E snow depth algorithm: Description and initial results, Journal of the Remote Sensing Society of Japan, 29, 307-317, 2009.

Kern, M., Cullen, R., Berruti, B., Bouffard, J., Casal, T., Drinkwater, M. R., Gabriele, A., Lecuyot, A., Ludwig, M., Midthassel, R., et al.: The Copernicus Polar Ice and Snow Topography Altimeter (CRISTAL) high-priority candidate mission, The Cryosphere, 14, 2235-2251, 7102020.

Kern, S., Khvorostovsky, K., Skourup, H., Rinne, E., Parsakhoo, Z., Djepa, V., Wadhams, P., and Sandven, S.: The impact of snow depth, snow density and ice density on sea ice thickness retrieval from satellite radar altimetry: results from the ESA-CCI Sea Ice ECV Project Round Robin Exercise, Cryosphere, 9, 37-52, 2015.

King, J., Howell, S., Derksen, C., Rutter, N., Toose, P., Beckers, J. F., Haas, C., Kurtz, N., and Richter-Menge, J.: Evaluation of Operation IceBridge quick-look snow depth estimates on sea ice, Geophysical Research Letters, 42, 9302-9310, https://doi.org/10.1002/2015GL066389, https://agupubs.onlinelibrary.wiley.com/doi/abs/10.1002/2015GL066389, 2015.

Koenig, L., Martin, S., Studinger, M., and Sonntag, J.: Polar Airborne Observations Fill Gap in Satellite Data, Eos, Transactions American Geophysical Union, 91, 333-334, https://doi.org/10.1029/2010EO380002, https://agupubs.onlinelibrary.wiley.com/doi/abs/10.1029/ 2010EO380002, 2010.

Kurtz, N., Studinger, M., Harbeck, J., Onana, V., and Farrell, S.: IceBridge sea ice freeboard, snow depth, and thickness, Digital media, NASA Distributed Active Archive Center at the National Snow and Ice Data Center, Boulder, Colorado, USA, http://nsidc. org/data/idcsi2., 2012 (Updated 2015). 
https://doi.org/10.5194/tc-2021-79

Preprint. Discussion started: 13 April 2021

(c) Author(s) 2021. CC BY 4.0 License.

(c) (i)

Kurtz, N., Farrell, S., Studinger, M., Galin, N., Harbeck, J., Lindsay, R., Onana, V., Panzer, B., and Sonntag, J.: Sea ice thickness, freeboard, and snow depth products from Operation IceBridge airborne data, The Cryosphere, 7, 1035-1056, https://doi.org/10.5194/tc-7-1035-2013, 2013.

Kurtz, N. T. and Farrell, S. L.: Large-scale surveys of snow depth on Arctic sea ice from Operation IceBridge, Geophysical Research Letters, 38, https://doi.org/10.1029/2011GL049216, https://agupubs.onlinelibrary.wiley.com/doi/abs/10.1029/2011GL049216, 2011.

Kwok, R. and Cunningham, G.: Variability of Arctic sea ice thickness and volume from CryoSat-2, Phil. Trans. R. Soc. A, 373 , 20140 157, 2015.

Kwok, R., Panzer, B., Leuschen, C., Pang, S., Markus, T., Holt, B., and Gogineni, S.: Airborne surveys of snow depth over Arctic sea ice, Journal of Geophysical Research: Oceans, 116, 2011.

Kwok, R., Kurtz, N., Brucker, L., Ivanoff, A., Newman, T., Farrell, S., King, J., Howell, S., Webster, M., Paden, J., Leuschen, C., MacGregor, J., Richter-Menge, J., Harbeck, J., and Tschudi, M.: Intercomparison of snow depth retrievals over Arctic sea ice from radar data acquired by Operation IceBridge, The Cryosphere, 11, 2571-2593, https://doi.org/https://doi.org/10.5194/tc-11-2571-2017, 2017.

Kwok, R., Kacimi, S., Webster, M., Kurtz, N., and Petty, A.: Arctic Snow Depth and Sea Ice Thickness From ICESat-2 and CryoSat-2 Freeboards: A First Examination, Journal of Geophysical Research: Oceans, 125, e2019JC016 008, 2020.

Laforge, A., Fleury, S., Dinardo, S., Garnier, F., Remy, F., Benveniste, J., Bouffard, J., and Verley, J.: Toward improved sea ice freeboard observation with SAR altimetry using the physical retracker SAMOSA+, Advances in Space Research, 2020.

Landy, J. C., Tsamados, M., and Scharien, R. K.: A facet-based numerical model for simulating SAR altimeter echoes from heterogeneous sea ice surfaces, IEEE Transactions on Geoscience and Remote Sensing, 57, 4164-4180, 2019.

Landy, J. C., Petty, A. A., Tsamados, M., and Stroeve, J. C.: Sea ice roughness overlooked as a key source of uncertainty in CryoSat-2 ice freeboard retrievals, Journal of Geophysical Research: Oceans, 125, e2019JC015 820, 2020.

Lawrence, I. R., Tsamados, M. C., Stroeve, J. C., Armitage, T. W., and Ridout, A. L.: Estimating snow depth over Arctic sea ice from calibrated dual-frequency radar freeboards, The Cryosphere, 12, 3551-3564, 2018.

745 Laxon, S., Peacock, N., and Smith, D.: High interannual variability of sea ice thickness in the Arctic region, Nature, 425, $947,2003$.

Laxon, S. W., Giles, K. A., Ridout, A. L., Wingham, D. J., Willatt, R., Cullen, R., Kwok, R., Schweiger, A., Zhang, J., Haas, C., et al.: CryoSat-2 estimates of Arctic sea ice thickness and volume, Geophysical Research Letters, 40, 732-737, 2013.

Lecomte, O., Fichefet, T., Vancoppenolle, M., and Nicolaus, M.: A new snow thermodynamic scheme for large-scale sea-ice models, Annals of Glaciology, 52, 337-346, 2011.

Ledley, T. S.: Snow on sea ice: Competing effects in shaping climate, Journal of Geophysical Research: Atmospheres, 96, 17 195-17 208, 1991.

Lee, Y.-K., Kongoli, C., and Key, J.: An in-depth evaluation of heritage algorithms for snow cover and snow depth using AMSR-E and AMSR2 measurements, Journal of Atmospheric and Oceanic Technology, 32, 2319-2336, 2015.

Lellouche, J.-M., Greiner, E., Le Galloudec, O., Garric, G., Regnier, C., Drevillon, M., Benkiran, M., Testut, C.-E., Bourdalle-Badie, R., Gasparin, F., Hernandez, O., Levier, B., Drillet, Y., Remy, E., and Le Traon, P.-Y.: Recent updates to the Copernicus Marine Service global ocean monitoring and forecasting real-time $1 / 12^{\circ}$ high-resolution system, Ocean Science, 14, 1093-1126, https://doi.org/10.5194/os-141093-2018, https://www.ocean-sci.net/14/1093/2018/, 2018.

Leonard, K. C. and Maksym, T.: The importance of wind-blown snow redistribution to snow accumulation on Bellingshausen Sea ice, Annals of Glaciology, 52, 271-278, 2011. 
https://doi.org/10.5194/tc-2021-79

Preprint. Discussion started: 13 April 2021

(C) Author(s) 2021. CC BY 4.0 License.

(c) (i)

Liston, G. E., Itkin, P., Stroeve, J., Tschudi, M., Stewart, J. S., Pedersen, S. H., Reinking, A. K., and Elder, K.: A Lagrangian Snow-Evolution System for Sea-Ice Applications (SnowModel-LG): Part I-Model Description, Journal of Geophysical Research: Oceans, 125, e2019JC015 913, https://doi.org/https://doi.org/10.1029/2019JC015913, https://agupubs.onlinelibrary.wiley.com/doi/abs/10. 1029/2019JC015913, e2019JC015913 2019JC015913, 2020.

Lundberg, A., Richardson-Näslund, C., and Andersson, C.: Snow density variations: consequences for ground-penetrating radar, Hydrological Processes, 20, 1483-1495, https://doi.org/https://doi.org/10.1002/hyp.5944, https://onlinelibrary.wiley.com/doi/abs/10.1002/hyp.5944, 2006.

Maaß, N., Kaleschke, L., Tian-Kunze, X., and Drusch, M.: Snow thickness retrieval over thick Arctic sea ice using SMOS satellite data, The Cryosphere, 7, 1971, 2013.

Madec, G. et al.: NEMO ocean engine, 2015.

Maksym, T. and Markus, T.: Antarctic sea ice thickness and snow-to-ice conversion from atmospheric reanalysis and passive microwave snow depth, Journal of Geophysical Research: Oceans, 113, https://doi.org/https://doi.org/10.1029/2006JC004085, 2008.

Mäkynen, M., Haapala, J., Aulicino, G., Balan-Sarojini, B., Balmaseda, M., Gegiuc, A., Girard-Ardhuin, F., Hendricks, S., Heygster, G., Istomina, L., et al.: Satellite Observations for Detecting and Forecasting Sea-Ice Conditions: A Summary of Advances Made in the SPICES Project by the EU's Horizon 2020 Programme, Remote Sensing, 12, 1214, 2020.

Mallett, R. D. C., Lawrence, I. R., Stroeve, J. C., Landy, J. C., and Tsamados, M.: Brief communication: Conventional assumptions involving the speed of radar waves in snow introduce systematic underestimates to sea ice thickness and seasonal growth rate estimates, The Cryosphere, 14, 251-260, https://doi.org/10.5194/tc-14-251-2020, https://www.the-cryosphere.net/14/251/2020/, 2020.

Markus, T. and Cavalieri, D. J.: Snow depth distribution over sea ice in the Southern Ocean from satellite passive microwave data, Antarctic sea ice: physical processes, interactions and variability, pp. 19-39, 1998.

Massom, R. A., Drinkwater, M. R., and Haas, C.: Winter snow cover on sea ice in the Weddell Sea, Journal of Geophysical Research: Oceans, 102, 1101-1117, https://doi.org/10.1029/96JC02992, https://agupubs.onlinelibrary.wiley.com/doi/abs/10.1029/96JC02992, 1997.

Massom, R. A., Eicken, H., Hass, C., Jeffries, M. O., Drinkwater, M. R., Sturm, M., Worby, A. P., Wu, X., Lytle, V. I., Ushio, S., et al.: Snow on Antarctic sea ice, Reviews of Geophysics, 39, 413-445, 2001.

Massom, R. A., Worby, A., Lytle, V., Markus, T., Allison, I., Scambos, T., Enomoto, H., Tamura, T., Tateyama, K., Haran, T., et al.: ARISE (Antarctic Remote Ice Sensing Experiment) in the East 2003: Validation of satellite-derived sea-ice data products, Annals of Glaciology, 44, 288-296, 2006.

Meier, W., Markus, T., and Comiso, J.: AMSR-E/AMSR2 unified L3 Daily $12.5 \mathrm{~km}$ Brightness Temperatures, Sea Ice Concentration, Motion and Snow Depth Polar Grids, Version 1., NASA National Snow and Ice Data Center Distributed archive Center, https://doi.org/https://doi.org/10.5067/RA1MIJOYPK3P., 2018.

Merkouriadi, I., Cheng, B., Graham, R. M., Rösel, A., and Granskog, M. A.: Critical Role of Snow on Sea Ice Growth in the Atlantic Sector of the Arctic Ocean, Geophysical Research Letters, 44, 10,479-10,485, https://doi.org/10.1002/2017GL075494, https://agupubs. onlinelibrary.wiley.com/doi/abs/10.1002/2017GL075494, 2017.

Nandan, V., Scharien, R. K., Geldsetzer, T., Kwok, R., Yackel, J. J., Mahmud, M. S., Rösel, A., Tonboe, R., Granskog, M., Willatt, R., Stroeve, J., Nomura, D., and Frey, M.: Snow Property Controls on Modeled Ku-Band Altimeter Estimates of First-Year Sea Ice Thickness: Case Studies From the Canadian and Norwegian Arctic, IEEE Journal of Selected Topics in Applied Earth Observations and Remote Sensing, 13, 1082-1096, https://doi.org/10.1109/JSTARS.2020.2966432, 2020. 
https://doi.org/10.5194/tc-2021-79

Preprint. Discussion started: 13 April 2021

(c) Author(s) 2021. CC BY 4.0 License.

(c) (i)

Newman, T., Farrell, S. L., Richter-Menge, J., Connor, L. N., Kurtz, N. T., Elder, B. C., and McAdoo, D.: Assessment of radar-derived snow depth over A rctic sea ice, Journal of Geophysical Research: Oceans, 119, 8578-8602, 2014.

Nghiem, S. V., Clemente-Colón, P., Douglas, T., Moore, C., Obrist, D., Perovich, D. K., Pratt, K. A., Rigor, I. G., Simpson, W., Shepson, P. B., et al.: Studying bromine, ozone, and mercury chemistry in the Arctic, Eos, Transactions American Geophysical Union, 94, 289-291, 2013.

Notz, D.: Challenges in simulating sea ice in Earth System Models, Wiley Interdisciplinary Reviews: Climate Change, 3, 509-526, 2012.

Parrinello, T., Shepherd, A., Bouffard, J., Badessi, S., Casal, T., Davidson, M., Fornari, M., Maestroni, E., and Scagliola, M.: CryoSat: ESA's ice mission - Eight years in space, Advances in Space Research, 62, 1178-1190, https://doi.org/https://doi.org/10.1016/j.asr.2018.04.014, https://www.sciencedirect.com/science/article/pii/S0273117718303296, the CryoSat Satellite Altimetry Mission: Eight Years of Scientific Exploitation, 2018.

Perovich, D., Richter-Menge, J., and Polashenski, C.: Observing and understanding climate change: Monitoring the mass balance, motion, and thickness of Arctic sea ice, http://imb-crrel-dartmouth.org, 2021.

Perovich, D.-K. and Richter-Menge: Regional variability in sea ice melt in a changing Arctic, Mathematical, physical and engineering sciences, 373, https://doi.org/http://doi.org/10.1098/rsta.2014.0165, 2015.

Perovich, D. K., Andreas, E. L., Curry, J. A., Eiken, H., Fairall, C. W., Grenfell, T. C., Guest, P., Intrieri, J., Kadko, D., Lindsay, R. W., McPhee, M. G., Morison, J., Moritz, R. E., Paulson, C. A., Pegau, W. S., Persson, P., Pinkel, R., Richter-Menge, J. A., Stanton, T., Stern, H., Sturm, M., Tucker III, W., and Uttal, T.: Year on ice gives climate insights, Eos, Transactions American Geophysical Union, 80, 481-486, https://doi.org/10.1029/EO080i041p00481-01, https://agupubs.onlinelibrary.wiley.com/doi/abs/10.1029/EO080i041p00481-01, 1999.

Perovich, D. K., Grenfell, T. C., Richter-Menge, J. A., Light, B., Tucker III, W. B., and Eicken, H.: Thin and thinner: Sea ice mass balance measurements during SHEBA, Journal of Geophysical Research: Oceans, 108, https://doi.org/10.1029/2001JC001079, https://agupubs onlinelibrary.wiley.com/doi/abs/10.1029/2001JC001079, 2003.

Petty, A. A., Webster, M., Boisvert, L., and Markus, T.: The NASA Eulerian Snow on Sea Ice Model (NESOSIM) v1.0: initial model development and analysis, Geoscientific Model Development, 11, 4577-4602, https://doi.org/10.5194/gmd-11-4577-2018, https://www. geosci-model-dev.net/11/4577/2018/, 2018.

Powell, D. C., Markus, T., and Stössel, A.: Effects of snow depth forcing on Southern Ocean sea ice simulations, Journal of Geophysical Research: Oceans, 110, 2005.

Richter-Menge, J. A., Perovich, D. K., Elder, B. C., Claffey, K., Rigor, I., and Ortmeyer, M.: Ice mass-balance buoys: a tool for measuring and attributing changes in the thickness of the Arctic sea-ice cover, Annals of Glaciology, 44, 205-210, 2006.

Ricker, R., Hendricks, S., Helm, V., Skourup, H., and Davidson, M.: Sensitivity of CryoSat-2 Arctic sea-ice freeboard and thickness on radar-waveform interpretation, Cryosphere, 8, 1607-1622, 2014.

Rostosky, P., Spreen, G., Farrell, S. L., Frost, T., Heygster, G., and Melsheimer, C.: Snow Depth Retrieval on Arctic Sea Ice From Passive Microwave Radiometers-Improvements and Extensions to Multiyear Ice Using Lower Frequencies, Journal of Geophysical Research: Oceans, 123, 7120-7138, 2018.

Schweiger, A., Lindsay, R., Zhang, J., Steele, M., Stern, H., and Kwok, R.: Uncertainty in modeled Arctic sea ice volume, Journal of Geophysical Research: Oceans, 116, https://doi.org/10.1029/2011JC007084, https://agupubs.onlinelibrary.wiley.com/doi/abs/10.1029/ 2011JC007084, 2011. 
https://doi.org/10.5194/tc-2021-79

Preprint. Discussion started: 13 April 2021

(c) Author(s) 2021. CC BY 4.0 License.

(c) (i)

Semenov, A., Zhang, X., Rinke, A., Dorn, W., and Dethloff, K.: Arctic intense summer storms and their impacts on sea ice-A regional climate modeling study, Atmosphere, 10, 218, 2019.

Serreze, M., Walsh, J., Chapin, F. S., Osterkamp, T., Dyurgerov, M., Romanovsky, V., Oechel, W., Morison, J., Zhang, T., and Barry, R.: Observational evidence of recent change in the northern high-latitude environment, Climatic change, 46, 159-207, 2000.

Shalina, E. V. and Sandven, S.: Snow depth on Arctic sea ice from historical in situ data, The Cryosphere, 12, $1867,2018$.

Singarayer, J. S., Bamber, J. L., and Valdes, P. J.: Twenty-first-century climate impacts from a declining Arctic sea ice cover, Journal of Climate, 19, 1109-1125, 2006.

Stewart, L. M., Dance, S. L., and Nichols, N. K.: Correlated observation errors in data assimilation, International Journal for Numerical Methods in Fluids, 56, 1521-1527, https://doi.org/https://doi.org/10.1002/fld.1636, https://onlinelibrary.wiley.com/doi/abs/10.1002/fld.1636, 2008.

Stroeve, J., Liston, G. E., Buzzard, S., Zhou, L., Mallett, R., Barrett, A., Tschudi, M., Tsamados, M., Itkin, P., and Stewart, J. S.: A Lagrangian Snow Evolution System for Sea Ice Applications (SnowModel-LG): Part II-Analyses, Journal of Geophysical Research: Oceans, 125, e2019JC015 900, https://doi.org/https://doi.org/10.1029/2019JC015900, https://agupubs.onlinelibrary.wiley.com/doi/abs/10. 1029/2019JC015900, e2019JC015900 2019JC015900, 2020.

Sturm, M. and Massom, R.: Snow in the sea ice system: Friend or foe?, pp. 65-109, https://doi.org/10.1002/9781118778371.ch3, 2016.

Sturm, M. and Massom, R. A.: Snow and sea ice, Sea ice, 2, 153-204, 2009.

850 Sturm, M., Holmgren, J., König, M., and Morris, K.: The thermal conductivity of seasonal snow, Journal of Glaciology, 43, $26-41$, 1997.

Sturm, M., Holmgren, J., and Perovich, D. K.: Winter snow cover on the sea ice of the Arctic Ocean at the Surface Heat Budget of the Arctic Ocean (SHEBA): Temporal evolution and spatial variability, Journal of Geophysical Research: Oceans, 107, SHE 23-1-SHE 23-17, https://doi.org/10.1029/2000JC000400, https://agupubs.onlinelibrary.wiley.com/doi/abs/10.1029/2000JC000400, 2002.

Sturm, M., Maslanik, J. A., Perovich, D., Stroeve, J. C., Richter-Menge, J., Markus, T., Holmgren, J., Heinrichs, J. F., and Tape, K.: Snow depth and ice thickness measurements from the Beaufort and Chukchi Seas collected during the AMSR-Ice03 campaign, IEEE transactions on Geoscience and Remote Sensing, 44, 3009-3020, 2006.

Ulaby, F., Moore, R. K., and Fung, A. K.: Microwave remote sensing: Active and passive. Volume 3-From theory to applications, 1986.

Uotila, P., Goosse, H., Haines, K., Chevallier, M., Barthélemy, A., Bricaud, C., Carton, J., Fučkar, N., Garric, G., Iovino, D., et al.: An assessment of ten ocean reanalyses in the polar regions, Climate Dynamics, 52, 1613-1650, 2019.

860 Vancoppenolle, M., Bouillon, S., Fichefet, T., Goosse, H., Lecomte, O., Morales Maqueda, M., and Madec, G.: The Louvain-la-Neuve sea ice model, Notes du pole de modélisation, Institut Pierre-Simon Laplace (IPSL), Paris, France, 2012.

Warren, S. G., Rigor, I. G., Untersteiner, N., Radionov, V. F., Bryazgin, N. N., Aleksandrov, Y. I., and Colony, R.: Snow Depth on Arctic Sea Ice, Journal of Climate, 12, 1814-1829, https://doi.org/10.1175/1520-0442(1999)012<1814:SDOASI>2.0.CO;2, https://doi.org/10.1175/ 1520-0442(1999)012<1814:SDOASI >2.0.CO;2, 1999.

Webster, M. A., Rigor, I. G., Nghiem, S. V., Kurtz, N. T., Farrell, S. L., Perovich, D. K., and Sturm, M.: Interdecadal changes in snow depth on Arctic sea ice, Journal of Geophysical Research: Oceans, 119, 5395-5406, https://doi.org/https://doi.org/10.1002/2014JC009985, https://agupubs.onlinelibrary.wiley.com/doi/abs/10.1002/2014JC009985, 2014.

Willatt, R. C., Giles, K. A., Laxon, S. W., Stone-Drake, L., and Worby, A. P.: Field Investigations of Ku-Band Radar Penetration Into Snow Cover on Antarctic Sea Ice, IEEE Transactions on Geoscience and Remote Sensing, 48, 365-372, https://doi.org/10.1109/TGRS.2009.2028237, 2010. 
https://doi.org/10.5194/tc-2021-79

Preprint. Discussion started: 13 April 2021

(c) Author(s) 2021. CC BY 4.0 License.

(c) (1)

Wingham, D., Francis, C., Baker, S., Bouzinac, C., Brockley, D., Cullen, R., de Chateau-Thierry, P., Laxon, S., Mallow, U., Mavrocordatos, C., et al.: CryoSat: A mission to determine the fluctuations in Earth's land and marine ice fields, Advances in Space Research, 37, 841-871, 2006.

Worby, A. P., Geiger, C. A., Paget, M. J., Van Woert, M. L., Ackley, S. F., and DeLiberty, T. L.: Thickness distribution of Antarctic sea ice, Journal of Geophysical Research: Oceans, 113, 2008a.

Worby, A. P., Markus, T., Steer, A. D., Lytle, V. I., and Massom, R. A.: Evaluation of AMSR-E snow depth product over East Antarctic sea ice using in situ measurements and aerial photography, Journal of Geophysical Research: Oceans, 113, $2008 \mathrm{~b}$.

Worby, A. P., Steer, A., Lieser, J. L., Heil, P., Yi, D., Markus, T., Allison, I., Massom, R. A., Galin, N., and Zwally, J.: Regional-scale sea-ice and snow thickness distributions from in situ and satellite measurements over East Antarctica during SIPEX 2007, Deep Sea Research Part II: Topical Studies in Oceanography, 58, 1125-1136, 2011.

Zhang, J. and Rothrock, D. A.: Modeling Global Sea Ice with a Thickness and Enthalpy Distribution Model in Generalized Curvilinear Coordinates, Monthly Weather Review, 131, 845-861, https://doi.org/10.1175/1520-0493(2003)131<0845:MGSIWA>2.0.CO;2, https: //doi.org/10.1175/1520-0493(2003)131<0845:MGSIWA>2.0.CO2, 2003.

Zhou, L., Xu, S., Liu, J., and Wang, B.: On the retrieval of sea ice thickness and snow depth using concurrent laser altimetry and L-band remote sensing data, The Cryosphere, 12, 993, 2018.

Zhou, L., Stroeve, J., Xu, S., Petty, A., Tilling, R., Winstrup, M., Rostosky, P., Isobel R, L., Liston, Glen E, R. A., Tsamados, M., and Nandan, V.: Intercomparison of snow depth over sea ice from multiple methods, The Cryosphere, 2020a.

Zhou, L., Stroeve, J., Xu, S., Petty, A., Tilling, R., Winstrup, M., Rostosky, P., Lawrence, I. R., Liston, G. E., Ridout, A., et al.: Intercomparison of snow depth over sea ice from multiple methods, The Cryosphere Discussions, pp. 1-35, $2020 \mathrm{~b}$.

Zygmuntowska, M., Rampal, P., Ivanova, N., and Smedsrud, L. H.: Uncertainties in Arctic sea ice thickness and volume: new estimates and implications for trends, Arctic sea ice altimetry-advances and current uncertainties, 2014. 
https://doi.org/10.5194/tc-2021-79

Preprint. Discussion started: 13 April 2021

(c) Author(s) 2021. CC BY 4.0 License.

\section{Appendix A: Appendices}

\begin{tabular}{|c|c|c|c|c|c|c|c|}
\hline \multicolumn{2}{|l|}{ Arctic } & ASD & MERCATOR & PIOMAS & NESOSIM & W99m & DuST \\
\hline \multirow{6}{*}{ Interannual mean $(\mathrm{cm})$} & 11 & 10.3 & 2.5 & 7.8 & 9.7 & 14.9 & 17.1 \\
\hline & 12 & 10.6 & 4 & 10 & 11.9 & 15 & 17.5 \\
\hline & 01 & 11.4 & 6.5 & 14 & 14.8 & 17.1 & 18.1 \\
\hline & 02 & 12.4 & 8.8 & 17.5 & 18 & 18.8 & 19.1 \\
\hline & 03 & 13.8 & 10.8 & 20.9 & 20.7 & 20.4 & 20.3 \\
\hline & 04 & 15.3 & 11.6 & 23 & 22.38 & 19 & 20.9 \\
\hline \multicolumn{2}{|c|}{ Climatic mean } & 12.3 & 7.4 & 15.5 & 16.2 & 17.5 & 18.8 \\
\hline \multirow{6}{*}{ Interannual varibility $(\mathrm{cm})$} & 11 & 4.8 & 1.4 & 3 & 2.4 & 2 & 4.3 \\
\hline & 12 & 4.6 & 2 & 3.5 & 3 & 1.8 & 4 \\
\hline & 01 & 4.5 & 2.6 & 4 & 3.1 & 2.3 & 4.3 \\
\hline & 02 & 4.4 & 3 & 4.4 & 3.5 & 2.6 & 4.3 \\
\hline & 03 & 4.7 & 3.9 & 5.5 & 4.3 & 2.6 & 4.5 \\
\hline & 04 & 5.2 & 4.3 & 5.8 & 4.7 & 3 & 4.9 \\
\hline \multicolumn{2}{|l|}{ mean $\equiv \mathrm{MIV}$} & 4.7 & 2.9 & 4.4 & 3.5 & 2.4 & 4.4 \\
\hline \multirow{6}{*}{ Annual variability (cm) } & 2013-2014 & 4.2 & 3.3 & 5.5 & 5 & 4.3 & 4.3 \\
\hline & $2014-2015$ & 4 & 3.1 & 5.8 & 5 & 4.1 & 3.9 \\
\hline & $2015-2016$ & 4.1 & 2.7 & 4.7 & 4.1 & 3.8 & 4.2 \\
\hline & $2016-2017$ & 4.2 & 3.9 & 6.1 & 4.9 & 4.4 & 4.2 \\
\hline & $2017-2018$ & 4.2 & 4 & 6.9 & $\mathrm{x}$ & 3.6 & 3.8 \\
\hline & $2018-2019$ & 4.2 & 3.9 & 6.5 & - & 3.2 & - \\
\hline \multicolumn{2}{|l|}{ mean $\equiv$ MAV } & 4.18 & 3.5 & 5.9 & 4.8 & 3.9 & 4.1 \\
\hline
\end{tabular}

Table A1. Statistical comparison of the different snow depth estimations in the Arctic over the six winters of the 2013-2019 period. AMSR-

2's data are not indicated since only the months of March and April were available. 


\begin{tabular}{|c|c|c|c|c|c|}
\hline \multicolumn{2}{|l|}{ Antarctica } & ASD & MERCATOR & GIOMAS & AMSR-2 \\
\hline \multirow{6}{*}{ Interannual mean } & 05 & 14.9 & 10.2 & 26.1 & 17.3 \\
\hline & 06 & 15.2 & 12.8 & 29 & 18 \\
\hline & 07 & 16 & 16.9 & 33.5 & 18.7 \\
\hline & 08 & 16.7 & 21.3 & 37.3 & 19.2 \\
\hline & 09 & 17.8 & 25.2 & 40.5 & 17.4 \\
\hline & 10 & 19.7 & 26.5 & 41.2 & 15.2 \\
\hline \multicolumn{2}{|l|}{ climatic mean } & 16.7 & 18.8 & 34.6 & 17.6 \\
\hline \multirow{6}{*}{ Interannual varibility } & 05 & 6 & 3.5 & 8.4 & 5.6 \\
\hline & 06 & 5.9 & 4.5 & 7.8 & 5.5 \\
\hline & 07 & 5.9 & 5.2 & 7.1 & 5.5 \\
\hline & 08 & 5.6 & 5.6 & 6.6 & 5.3 \\
\hline & 09 & 6.2 & 6.1 & 6.5 & 4.9 \\
\hline & 10 & 7.4 & 6.7 & 7 & 5.3 \\
\hline \multicolumn{2}{|l|}{ mean $\equiv$ VIM } & 6.2 & 5.3 & 7.2 & 5.3 \\
\hline \multirow{7}{*}{ Annual variability } & 2013 & 5.5 & 6.7 & 7.5 & 4.1 \\
\hline & 2014 & 5.2 & 6.6 & 6.6 & 4.3 \\
\hline & 2015 & 5.1 & 6.8 & 6.4 & 3.7 \\
\hline & 2016 & 5.5 & 5.4 & 9.2 & 4.2 \\
\hline & 2017 & 5.6 & 6.4 & - & 3.7 \\
\hline & 2018 & 5.5 & 6.7 & - & 3.8 \\
\hline & 2019 & 5.4 & 6.0 & - & 4.1 \\
\hline \multicolumn{2}{|l|}{ mean $\equiv \mathbf{V A M}$} & 5.4 & 6.4 & 7.4 & 4 \\
\hline
\end{tabular}

Table A2. Statistical comparison of the different snow depth estimations in Antarctica over the seven winters of the 2013-2019 period. 
https://doi.org/10.5194/tc-2021-79

Preprint. Discussion started: 13 April 2021

(c) Author(s) 2021. CC BY 4.0 License.

\begin{tabular}{|c|c|c|c|c|c|c|c|c|}
\hline \multicolumn{2}{|c|}{ all snow products } & m11 & m12 & m01 & m02 & m03 & m04 & mean \\
\hline \multicolumn{2}{|c|}{ Mean } & 0.94 & 1.08 & 1.25 & 1.42 & 1.59 & 1.65 & 1.32 \\
\hline \multirow{3}{*}{ STD } & mean & 0.27 & 0.26 & 0.25 & 0.26 & 0.27 & 0.28 & 0.27 \\
\hline & $\min$ & 0.20 & 0.19 & 0.18 & 0.18 & 0.18 & 0.18 & 0.18 \\
\hline & $\max$ & 0.35 & 0.34 & 0.34 & 0.34 & 0.37 & 0.41 & 0.36 \\
\hline \multirow{3}{*}{ Max dev } & mean & 0.74 & 0.74 & 0.71 & 0.72 & 0.78 & 0.84 & 0.76 \\
\hline & $\min$ & 0.55 & 0.54 & 0.50 & 0.49 & 0.51 & 0.53 & 0.52 \\
\hline & $\max$ & 0.98 & 0.97 & 0.95 & 0.97 & 1.09 & 1.23 & 1.03 \\
\hline \multicolumn{2}{|c|}{ obs snow products } & m11 & m12 & m01 & m02 & m03 & m04 & mean \\
\hline \multicolumn{2}{|c|}{ Mean } & 1.09 & 1.21 & 1.34 & 1.48 & 1.62 & 1.65 & 1.40 \\
\hline \multirow{3}{*}{ STD } & mean & 0.21 & 0.21 & 0.21 & 0.20 & 0.19 & 0.19 & 0.20 \\
\hline & $\min$ & 0.10 & 0.11 & 0.10 & 0.10 & 0.09 & 0.08 & 0.09 \\
\hline & $\max$ & 0.32 & 0.32 & 0.31 & 0.30 & 0.31 & 0.30 & 0.31 \\
\hline \multirow{3}{*}{ Max dev } & mean & 0.51 & 0.52 & 0.50 & 0.48 & 0.47 & 0.47 & 0.49 \\
\hline & $\min$ & 0.24 & 0.24 & 0.24 & 0.23 & 0.22 & 0.20 & 0.23 \\
\hline & $\max$ & 0.78 & 0.80 & 0.78 & 0.75 & 0.76 & 0.77 & 0.77 \\
\hline
\end{tabular}

Table A3. Statistical impact of the various snow depths on SIT in the Arctic over the 2013-2019 time period. The upper part consider all the snow depth products while the upper part consider only the products based on observations (ASD, DuST, AMSR2B and W99m). We remind that AMSR2B SIT estimations on MYI are only taken into account for the months of March and April 